\title{
Pulsed Multiphase Flows-Numerical Investigation of Particle Dynamics in Pulsating Gas-Solid Flows at Elevated Temperatures
}

\author{
Arne Teiwes $^{1, *}$, Maksym Dosta $^{2} \mathbb{D}$, Michael Jacob ${ }^{1}$ and Stefan Heinrich ${ }^{2}$ D \\ 1 Glatt Ingenieurtechnik GmbH, 99427 Weimar, Germany; michael.jacob@glatt.com \\ 2 Institute of Solids Process Engineering and Particle Technology, Hamburg University of Technology, \\ 21073 Hamburg, Germany; dosta@tuhh.de (M.D.); stefan.heinrich@tuhh.de (S.H.) \\ * Correspondence: arne.teiwes@glatt.com
}

Received: 11 June 2020; Accepted: 3 July 2020; Published: 10 July 2020

\begin{abstract}
Although the benefits of pulsating multiphase flows and the concomitant opportunity to intensify heat and mass transfer processes for, e.g., drying, extraction or chemical reactions have been known for some time, the industrial implementation is still limited. This is particularly due to the lack of understanding of basic influencing factors, such as amplitude and frequency of the pulsating flow and the resulting particle dynamics. The pulsation generates oscillation of velocity, pressure, and temperature, intensifying the heat and mass transfer by a factor of up to five compared to stationary gas flow. With the goal of process intensification and targeted control of sub-processes or even the development of completely new processing routes for the formation, drying or conversion of particulate solids in pulsating gas flows as utilized in, e.g., pulse combustion drying or pulse combustion spray pyrolysis, the basic understanding of occurring transport processes is becoming more and more important. In the presented study, the influence of gas-flow conditions and particle properties on particle dynamics as well as particle residence time and the resulting heat and mass transfer in pulsating gas-solid flows are investigated.
\end{abstract}

Keywords: gas-solid processes; gas pulsation; spray processes; particle dynamics; heat and mass transfer

\section{Introduction}

Conventional spray-drying is commonly used for the continuous production of particulate or powdery materials from liquid raw materials such as solutions or solid-liquid dispersions as well as liquid-liquid dispersions. Mechanisms of particle formation are mostly dependent on two main factors: on one hand, on drying gas and liquid precursor properties, on the other hand, on droplet generation and the resulting droplet drying kinetics. The finally-produced solid particles are typically sub-micrometer or micrometer sized and have almost an ideal spherical shape. If the particle formation is based not only on drying but also on calcination or chemical conversion of liquid precursors by, e.g., oxidation or reduction at elevated temperatures, the term spray calcination or spray pyrolysis is used. Among others, spray pyrolysis is utilized for the production of metal oxide particles for catalyst or ceramic applications. Typical precursors are based on metal salt solutions or dispersions injected in the pyrolysis reactor as atomized liquids, simultaneously converted to desired metal oxide phases by drying, chemical conversion and phase transformation processes [1-3]. Furthermore, spray-drying and spray pyrolysis processes can be intensified by utilizing a pulsating gas flow [4-6], e.g., as pulse combustion drying or as pulse combustion spray pyrolysis according to the Advanced Pulse Powder technology APPtec ${ }^{\circledR}$ of Glatt Ingenieurtechnik GmbH [7]. 
There are several different designs and apparatus principles possible. Hot pulsating gas flows fed to the reaction or drying zone can be generated by pulse or pulsed combustors [4] or induced separated from heat generation with pulsation devices in combination with indirect heating of the gases [8]. The pulsation generates sinusoidal oscillation of velocity, pressure and temperature, with frequencies that vary in the range of 20 to $200 \mathrm{~Hz}$ with pressure oscillation amplitudes of up to \pm $10 \mathrm{kPa}$ [5]. In terms of pulse combustion drying, several benefits have been identified compared to stationary spray-drying. The most important benefits are:

- $\quad$ increased heat and mass transfer by a factor of $2-5$;

- higher product homogeneity;

- better product quality by eliminating distributions of characteristic process parameters such as temperature, concentration or moisture content in the drying equipment.

Even though these and other benefits are well known, industrial implementation for pulsed gas spray processes is still limited. This is mostly caused due to a lack of process understanding. There are no short-cut models or scale-up strategies where the influence of processing parameters like frequency and amplitude of the pulsation is considered [4-6,9].

In order to obtain a better understanding of transport processes and particle dynamics in pulsed multiphase flows, particularly reactor concepts and operating regimes for the APPtec ${ }^{\circledR}$ method, the effects of frequency and amplitude as well as particle properties on the overall process performance of pulse combustion spray pyrolysis are investigated in the presented study. With the help of the computational fluid dynamics method (CFD) simulations and the unilaterally coupled modeling of gas-particle micro-processes, parameter dependencies are highlighted with respect to single particle heat and mass transfer, particle residence times and particle yield at the outlet of the reactor.

The overall process principle of Glatts APPtec ${ }^{\circledR}$ is displayed in Figure 1. The process is set up by several steps. Process gas, up-stream of the reaction chamber (vertical pipe reactor with $L>>d$ ), is conditioned in terms of composition, gas temperature and pulsation parameters. This is either carried out by a specially-designed directly-fired natural gas combustor or-especially on a smaller scale-with electrical heating and separate pulsation generation.

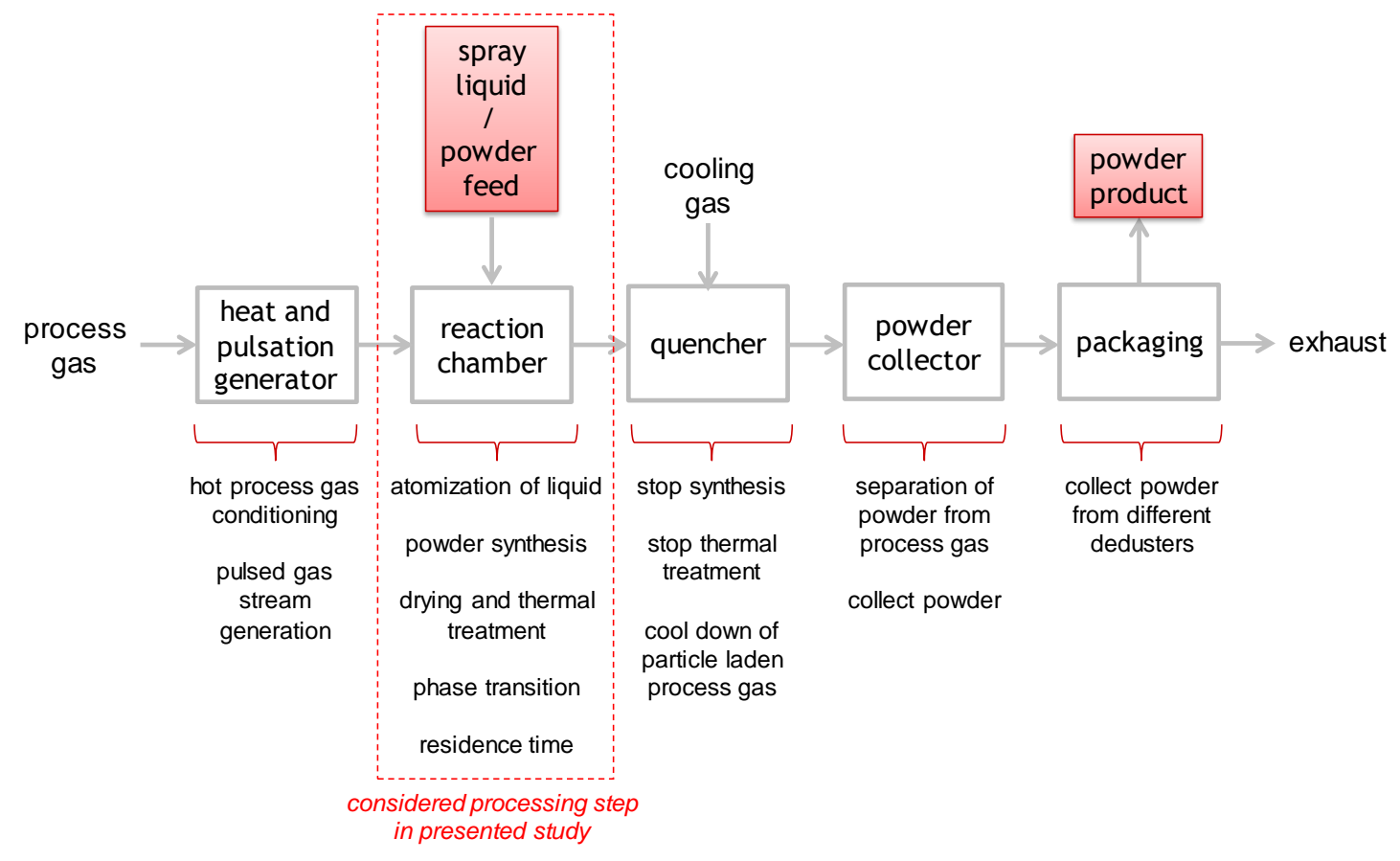

Figure 1. Overall process principle of Glatts APPtec ${ }^{\circledR}$. 
Conditioned process gas and the material feed are then introduced to the reactor in co-current upward flow. After treatment of the material by means of drying, chemical conversion or phase transition, the particle-laden process gas stream is quickly quenched by mixing in cold gas in order to stop thermal synthesis and treatment. Further down-stream, the particles are separated from the gas flow by different types and combinations of dedusters (e.g., cyclones, bag house filters or HEPA filters), collected and finally transferred to packaging by conveying.

\section{Materials and Methods}

Research work on pulsed multiphase flows, especially for the evaluation of injected sprays and resulting particle formation as well as particle dynamics in the operating regime of Glatt's APPtec ${ }^{\circledR}$ method, is very limited. In general, modeling and experimental studies on common pulse combustion and pulsed flows do exist, but they usually focus on very specific aspects of pulsating single-phase flow and pulse combustion, e.g., thermal efficiency or pollutant emissions. Due to the complexity of the pulse combustion process, many different theoretical and numerical zero-, one- or even multi-dimensional models on the basis of CFD were developed since the early 1950s [9]. Only a few studies were carried out focusing on particle dynamics, gas-particle relative velocities [10,11], resulting gas-particle heat and mass transfer [12,13] or droplet dispersion, droplet breakup and nanoparticle formation [13-15] or particle separation by coupled CFD-DEM approach [16] for pulsating flows, pulsed combustion drying or pulsating coal combustors in general. The modeling of pulsed multiphase flow was performed mostly with direct numerical simulation approaches and only for selected frequencies of specific pulsed combustor setups. The results show enhancements of the heat and mass transfer for single particles as well as particle grouping effects for collectives, that occur with pulsation. Carvalho Jr. [10] also found an effect on particle residence times, indicating a reduction of the residence time for pulsating flows compared to stationary flow. Research on the topic of pulse combustion spray pyrolysis is rather limited and mostly related to experimental work for the processing of very specific material systems, such as $\mathrm{ZnO}$ [6]. One distinctive feature of Glatt's APPtec ${ }^{\circledR}$ method is the adjustable frequency and amplitude of the pulsation independently of other crucial processing parameters like gas temperature and mean gas flow velocity, providing a wide range of operation regimes. Typical frequencies are in-between $40-160 \mathrm{~Hz}$ with pulsation pressure amplitudes of up to $5 \mathrm{kPa}$. Therefore, the influence of different combinations of these two parameters on particles of different properties (especially particle size) are of special interest for a deeper understanding of process behavior and resulting product properties.

In the present work, particle formation in pulsed multiphase flow is modelled in two subsequent stages. In the first stage, gas pulsation is simulated in a vertical cylindrical pipe reactor by computational fluid dynamics method (CFD) without consideration of the solid phase. Since the solid concentration in the considered reactor with analysis of single particles is low, it is assumed that the individual particles have no influence on gas dynamics. Afterwards, obtained CFD data are revaluated and resulting flow profiles for different pulsation frequencies and amplitudes are extracted for one sinusoidal pulsation period. The extraction is started only after the stabilization of transient oscillations at the quasi-stationary point. Extracted data text files are reorganized and thereby prepared for further analysis during modeling of the solid phase. The obtained time-dependent fluid profile is then transferred to the second model, where simulation of single particle dynamics as well as heat and mass transfer is performed. A similar approach has been effectively used for the modeling of liquid injection into fluidized beds [17-19].

\subsection{Modeling of Fluid Flow}

In this contribution, for CFD calculations, the open source tool OpenFOAM ${ }^{\circledR}$ (Version 2.4.X, TheOpenFOAMFoundation Ltd., London, UK, 2011 - 2020) was used [20]. The geometry of the vertical cylindrical process chamber $\left(\mathrm{d}_{\mathrm{cyl}}=0.1 \mathrm{~m}, \mathrm{H}_{\text {cyl }}=1 \mathrm{~m}\right.$, see Figure 2) was drawn in CAD software SolidWorks ${ }^{\circledR}$ and the simulation mesh was generated with hexahedral cut-cell-based OpenFOAM ${ }^{\circledR}$ meshing tool snappyHexMesh. Meshing was performed with addition of 5 layers for higher resolution 
in the wall region of the cylindrical volume and a cell refinement level of 3 . For the underlying block mesh, a mesh independency test was carried out. Four different refinement levels were simulated. Block mesh cell sizes $\Delta x$ of $10 \mathrm{~mm} ; 5 \mathrm{~mm} ; 2.5 \mathrm{~mm}$ and $1 \mathrm{~mm}$ were used. For comparison of results, the velocity profiles at heights of $z=0.05$ Tablem and $z=0.95 \mathrm{~m}$ as well as pressure profiles at these points were compared. The percentual difference of results compared to the smallest cell size $\Delta x$ of $1 \mathrm{~mm}$ were up to $50 \%$ for the case of $10 \mathrm{~mm}$, up to $10 \%$ for the case of $5 \mathrm{~mm}$ and maximum $2.5 \%$ for $2.5 \mathrm{~mm}$. Based on the comparison of accuracy and calculation time, a block mesh cell size $\Delta x$ of $2.5 \mathrm{~mm}$ $\left(2.5 \ldots 10\right.$ times particle diameter $\left.d_{p}\right)$ with a total of 640,000 cells was chosen. After the addition of layers and the refinement of cells, in total, the simulation mesh contained around 1,715,000 cells of mostly hexahedral type (see Figure 2).

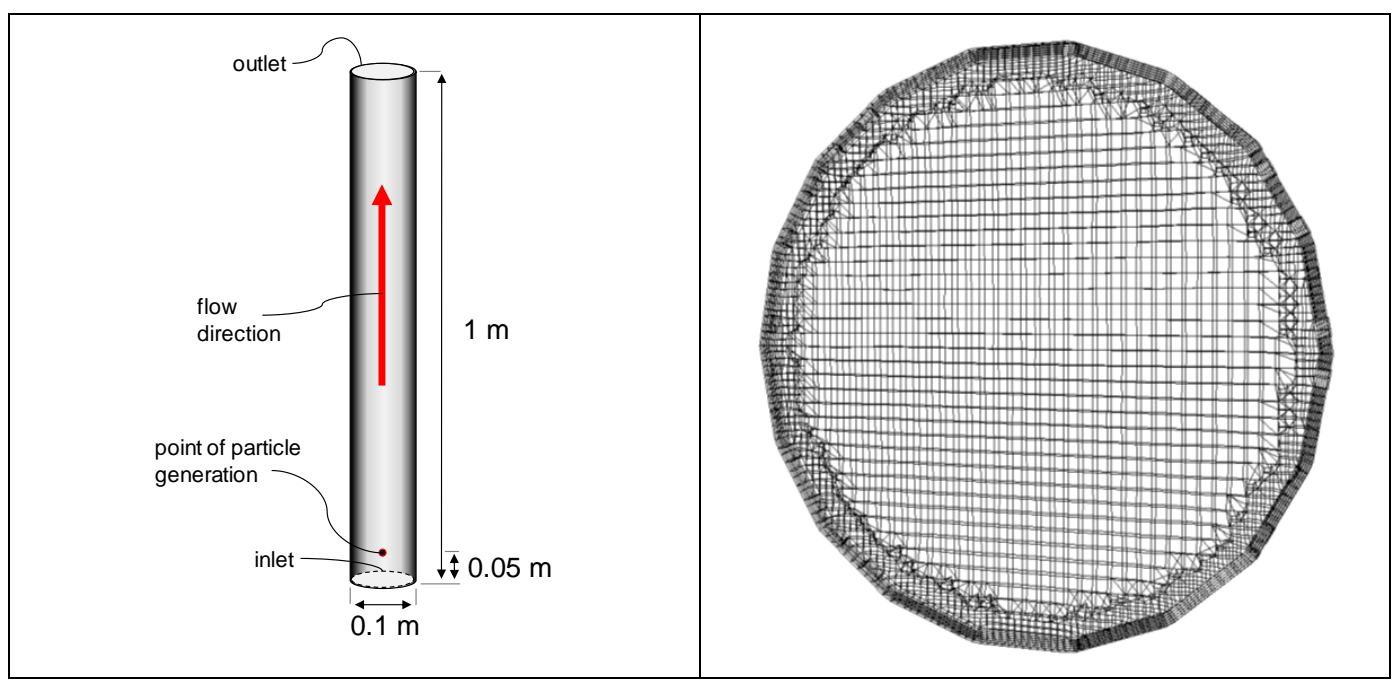

Figure 2. Left: Geometry of the vertical cylindrical process chamber. Right: Cross-sectional view of one cell plane for fluid flow simulations containing of 1,715,000 with maximum cell size of $2.5 \mathrm{~mm}$.

Simulations were carried out using the built-in SprayFOAM solver for solving combustion problems of sprays, also considering acoustic phenomena. The solver is generally based on the PIMPLE algorithm, which is a combined algorithm of the Semi-Implicit method for Pressure Linked Equations (SIMPLE) and Pressure Implicit with Splitting of Operator (PISO). Simulations were performed for turbulent flows of compressible fluids using the standard k- $\varepsilon$-model and Reynolds-Averaged Navier-Stokes equations (RANS). Pulsation has been modelled with a time-dependent sinusoidal gas velocity defined in the vertical direction $(\mathrm{z})$ :

$$
u_{\mathrm{z}}(t)=u_{\mathrm{z}, 0}-u_{\max } \cdot \sin \left(2 \pi f_{\mathrm{puls}} t+\varphi\right)
$$

where $u_{\mathrm{z}, 0}$ is the mean vertical flow velocity, $u_{\max }$ is the pulsation velocity amplitude, $\varphi$ is the angular phase shift and $f_{\text {puls }}$ is pulsation frequency. The inlet velocities in radial $(x, y)$ direction were equal to zero.

In this study, several gas flow profiles were simulated. The parameters of the investigated profiles are listed in Table 1. The parameters, except pulsation velocity amplitude, were chosen based on typical operating parameters of Glatts APPtec ${ }^{\circledR}$ measured with the powder synthesis plant ProAPP500 ${ }^{\circledR}$. These parameters define the chosen boundary conditions for the numerical investigation. Since the acoustic behavior of the overall plant ProAPP500 is not only determined by the geometry of the pyrolysis reactor pipe, but also by duct work and gas-solid separation units, like cyclones and filters, the acoustic behavior in terms of resonance differs from the simplified reactor (only) model volume investigated in this study. Resulting pulsation amplitudes from excitation based on the chosen boundary conditions are shown and further explained in Section 3.1. 
Table 1. Parameters for Equation (1) varied in simulation case studies.

\begin{tabular}{cccc}
\hline Parameter & Symbol & Value & Unit \\
\hline Mean vertical gas flow velocity & $\mathrm{u}_{\mathrm{z}, 0}$ & 6 & $\mathrm{~m} / \mathrm{s}$ \\
Angular phase shift & $\varphi$ & 0 & - \\
Pulsation pressure amplitude & $\mathrm{p}_{\max }$ & $0^{1} ; 1 ; 2$ and 4 & $\mathrm{kPa}$ \\
Pulsation velocity amplitude & $\mathrm{u}_{\max }$ & $0^{1} ; 3 ; 6$ and 12 & $\mathrm{~m} / \mathrm{s}$ \\
Pulsation frequency & $\mathrm{f}_{\text {puls }}$ & $0^{1} ; 40 ; 80$ and 160 & $\mathrm{~Hz}$ \\
\hline
\end{tabular}

${ }^{1}$ Reflects the stationary simulation case for comparison.

The pulsation velocity amplitude is a necessary simulation parameter derived from the pulsation frequency and pressure amplitude. Based on the theory of acoustics, the velocity pulsation amplitude $u_{\max }$ is equal to the sound particle velocity $u_{\mathrm{eff}}$, which is a function of the root mean square of the pressure amplitude, the speed of sound $c_{\max }$ and the density of the gas $\rho_{G}$ at a given temperature.

$$
\mathrm{u}_{\max }=\mathrm{u}_{\mathrm{eff}}=\frac{\mathrm{p}_{\max }}{\sqrt{2} \cdot \mathrm{c}_{\max }(\mathrm{T}) \cdot \rho_{\mathrm{G}}(\mathrm{T})}
$$

The basis for the pulsation pressure amplitude are measured values at typical operation regimes of the powder synthesis plant ProAPP500 ${ }^{\circledR}$. For the measurement, a fast, dynamic pressure measurement with online fast Fourier transformation is used to analyze main frequencies and their respective pressure amplitudes.

In total, the variation of listed parameters provides a set of 10 different fluid flow simulations: 9 simulations with pulsation and one stationary fluid flow simulation for comparison. All other inlet condition parameters kept constant in all simulations are listed in Table 2. In order to not overdetermine the simulation system, thermodynamic gas properties are only defined either for the inlet or the outlet of the model volume. Temperature $\left(\mathrm{T}_{\text {outlet }}\right)$, velocity $\left(\mathrm{u}_{\text {outlet }}\right)$ at outlet and pressure $\left(\mathrm{p}_{\text {inlet }}\right)$ at inlet are defined as "zero gradient" and directly calculated from the given boundary conditions during simulation. Pressure at the outlet is set to ambient conditions to simulate an open pipe to the environment. Time-dependent pressure pulsation in the cylindrical volume results from the defined sinusoidal velocity excitation at the inlet. A no-slip condition is assumed for all fluid-solid boundaries, so that the gas phase will have zero velocity relative to the wall boundary. Simulation time steps and saving intervals are dependent on the actual simulated pulsation frequency and amplitude. The simulation time steps are set to be adjustable by the solver and calculated on the basis of a maximum Courant-Number $\mathrm{Co}=0.75$ [21].

$$
\mathrm{Co}=\mathrm{u} \cdot \frac{\Delta \mathrm{x}}{\Delta \mathrm{t}}=0.75
$$

where $\Delta t$ is the simulation time step, $\Delta x$ is the cell size and $u$ is the flow velocity.

\begin{tabular}{|c|c|c|c|}
\hline Parameter & Symbol & Value & Unit \\
\hline Gas flow velocity at outlet & $\begin{array}{c}\mathrm{u}_{\text {outlet }} \\
\text { Gas composition }\end{array}$ & "zero gradient" & $\mathrm{m} / \mathrm{s}$ \\
\hline Oxygen mass fraction & $\mathrm{w}_{\mathrm{O} 2 \text {,inlet }}$ & 0.234 & $\mathrm{~kg} / \mathrm{kg}$ \\
\hline Nitrogen mass fraction & $\mathrm{W}_{\mathrm{N} 2 \text {,inlet }}$ & 0.766 & $\mathrm{~kg} / \mathrm{kg}$ \\
\hline \multicolumn{4}{|c|}{ Thermodynamic gas properties } \\
\hline Gas temperature at inlet & $\mathrm{T}_{\text {inlet }}$ & 800 & $\mathrm{~K}$ \\
\hline Gas temperature at outlet & $\mathrm{T}_{\text {outlet }}$ & "zero gradient" & K \\
\hline Gas pressure at inlet & pinlet & "zero gradient" & $\mathrm{kPa}$ \\
\hline Gas pressure at outlet & poutlet & 100 & $\mathrm{kPa}$ \\
\hline
\end{tabular}

Table 2. Constant simulation parameters. 
The saving interval of obtained data is chosen to be $1 / 10$ of the duration of a single pulsation period which is dependent on the simulated pulsation frequency. The sampling frequency $f_{\text {samp }}$ is therefore 10 times the pulsation frequency $f_{\text {puls }}$.

$$
\mathrm{f}_{\mathrm{samp}}=10 \cdot \mathrm{f}_{\text {puls }} \text {. }
$$

\subsection{Modeling of Solid Phase}

For the modeling of particle dynamics in the reactor, a separate sub-model was developed and implemented in $\mathrm{C}++$ programming language. Here, the single particles are generated in the injection zone and afterwards each particle is treated as a separate discrete entity. It is supposed that in a steady-state regime, the gas profile is the same for different pulsation periods. Therefore, the fluid profile extracted from CFD calculations for one pulsation period is recursively repeated for a longer time interval. The fluid flow profile for one pulsation period is represented by 10 equidistant time points. Each time point is exported from the CFD calculations as an individual text file. To extract information about flow profile at any arbitrary time, linear interpolation was used. To be able to evaluate the single particle dynamics at any time and any condition of injection 40,000 particles per second are considered and simulated simultaneously.

Three main groups of time-dependent particle characteristics are studied in this contribution:

- $\quad$ single particle dynamics: trajectory, velocity and acceleration;

- thermal evolution: temperature, heat and enthalpy flux;

- species evolution: concentration, mass flux and size change.

To simulate time-dependent change of particle properties, the whole simulation time was discretized into smaller simulation time steps of constant size, and calculations were performed iteratively. All temperature-dependent thermodynamic properties of the fluids, such as, e.g., evaporation enthalpy, dynamic viscosity or heat conductivity, are calculated according to [22] and will not be explained in further detail.

\subsubsection{Particle Dynamics}

Particle dynamics were modeled with certain simplifications and assumptions. It is assumed that all particles are spherical and have the same initial size and composition. Particle-particle interaction, particle breakage or agglomeration, as well as an influence of the solid phase on gas flow are neglected. For the modeling of particle-wall interactions, it is assumed that if a particle collides with any part of the geometry, it sticks to its surface and no rebound occurs. Furthermore, a homogeneous temperature profile inside of each particle is assumed. Thus, heat conduction inside of the particles is not considered. Particle shrinking caused by the evaporation of solvent is assumed to be dependent only on the loss of volume of the solvent.

Relative velocities $u_{\text {rel }}$ between particles and surrounding fluid are calculated for any time point $t$ and particle $\mathrm{i}$ as the difference between gas and particle velocity $u$ and $v$ in all three coordinates $\mathrm{x}$, $\mathrm{y}$ and $\mathrm{z}$. To obtain gas properties such as flow velocity or temperature, the closest node to the position of the particle in the 3D simulation volume is selected

$$
\mathrm{u}_{\mathrm{rel}, \mathrm{i}}(\mathrm{t})=\mathrm{u}_{\mathrm{i}}(\mathrm{t})-\mathrm{v}_{\mathrm{i}}(\mathrm{t})
$$

The particle Reynolds number $R e_{\mathrm{p}}$ is derived by Equation (6), where $\rho_{\mathrm{f}}$ is the density of the fluid, $\eta_{\mathrm{f}}$ is the dynamic viscosity of the fluid and $r_{\mathrm{p}}$ is the time-dependent particle radius. The dynamic viscosity and density of the surrounding gas are calculated for each particle and time point separately. 
Depending on the particle's position, the temperature of the gas of the closest node is used for the calculation of temperature-dependent gas properties as described in Section 2.2.2.

$$
\operatorname{Re}_{p, i}(t)=\frac{\rho_{f, i}(t) \cdot u_{r e l, i}(t) \cdot 2 \cdot r_{p, i}(t)}{\eta_{f, i}(t)} .
$$

The drag coefficient $C_{\mathrm{D}}$ is dependent on the particle Reynolds number $\mathrm{Re}_{\mathrm{p}}$. For spherical particles and $R e_{\mathrm{p}}<10^{5}$ the drag coefficient is calculated with the correlation of [23] described by:

$$
C_{D, i}(t)=\frac{24}{\operatorname{Re}_{p, i}(t)}+\frac{4}{\operatorname{Re}_{p, i}(t)^{0,5}}+0.4
$$

The change in the velocity of the individual particle is estimated through its momentum balance. The net forces acting on the particle constitute the downward gravity force, the upward drag force and buoyancy. In this contribution the buoyancy force is neglected and resulting forces $\mathrm{F}$ are described by:

$$
F_{i}(t)=0.5 \cdot \rho_{f, i}(t) \cdot C_{D, i}(t) \cdot \pi \cdot r_{p, i}(t)^{2} \cdot u_{r e l, i}(t)^{2}+F_{g, i}(t) .
$$

Note, that due to the evaporation, the mass of particles is not constant. Detailed explanations regarding mass loss are given in the following sections related to heat and mass transfer.

To calculate changes of particle velocities $v_{\mathrm{i}}$ and coordinates $X_{\mathrm{p}, \mathrm{i}}$ for each following time step $\mathrm{t}+\Delta \mathrm{t}$ the Euler integration scheme is used:

$$
\begin{gathered}
v_{i}(t+\Delta t)=v_{i}(t)+\frac{\Delta t \cdot F_{i}(t)}{m_{p, i}(t)} \\
X_{p, i}(t+\Delta t)=X_{p, i}(t)+\Delta t \cdot v_{i}(t) .
\end{gathered}
$$

\subsubsection{Heat Transfer}

Thermal evolution of the particles depends on heat transfer from the surrounding gas to the particle and on solvent evaporation. The empirical Ranz and Marshall correlation defines the heat transfer between a spherical particle and the surrounding gas for a wide range of thermodynamic properties $[24,25]$. The calculation of the individual particle Nusselt number $\mathrm{Nu}$ thereby is given as:

$$
N u_{\mathrm{p}, \mathrm{i}}(t)=2+0.6 \cdot R e_{\mathrm{p}, \mathrm{i}}(t)^{\frac{1}{2}} \cdot \operatorname{Pr} r_{\mathrm{i}}(t)^{\frac{1}{3}},
$$

with the Prandtl number $P r$, where $c_{P, f, i}$ is the specific heat capacity of the fluid at constant pressure and $\lambda_{\mathrm{f}, \mathrm{i}}$ is the heat conductivity of the fluid and. Fluid parameters like $\lambda_{\mathrm{f}, \mathrm{i}}$ or the dynamic viscosity $\eta_{f, i}$ are directly derived from fluid flow simulation results at the closest node to the particle $i$. Temperature- and pressure-dependent parameters are then calculated with polynomial functions from VDI-Wärmeatlas [22]:

$$
\operatorname{Pr}_{i}(t)=\frac{\eta_{f, i}(t) \cdot c_{P, f, i}(t)}{\lambda_{f, i}(t)}
$$

The individual gas-particle heat transfer coefficient $h$ is derived from the Nusselt number obtained by Equation (11).

$$
h_{i}(t)=\frac{N u_{p, i}(t) \cdot \lambda_{f, i}(t)}{r_{p, i}(t)^{2}} .
$$

The resulting heat flow $\mathrm{Q}$ to the individual particle is described by Equation (14):

$$
\dot{\mathrm{Q}}_{\mathrm{i}}(\mathrm{t})=\mathrm{h}_{\mathrm{i}}(\mathrm{t}) \cdot 4 \pi \cdot \mathrm{r}_{\mathrm{p}, \mathrm{i}}(\mathrm{t})^{2} \cdot\left(\mathrm{T}_{\mathrm{f}, \mathrm{i}}(\mathrm{t})-\mathrm{T}_{\mathrm{p}, \mathrm{i}}(\mathrm{t})\right)
$$


where $T_{\mathrm{f}, \mathrm{i}}$ and $T_{\mathrm{p}, \mathrm{i}}$ are the time-dependent temperature of fluid and individual particle. The changes in particle temperature for each time step are calculated with respect to mass transfer and evaporation enthalpy of the liquid according to Equation (26) of Section 2.2.3.

\subsubsection{Mass Transfer}

Species evolution of the particles is based upon mass transfer from the particle to the surrounding gases and vice versa. In analogy to heat transfer, the empirical Ranz and Marshall correlation can be used for mass transfer calculations between a spherical particle and the surrounding gas [24]. The calculation of the individual particle Sherwood number $S h_{\mathrm{p}, \mathrm{i}}$ thereby is given as:

$$
\mathrm{Sh}_{\mathrm{p}, \mathrm{i}}(\mathrm{t})=2+0.6 \cdot \operatorname{Re}_{\mathrm{p}, \mathrm{i}}(\mathrm{t})^{\frac{1}{2}} \cdot \mathrm{Sc}_{\mathrm{i}}(\mathrm{t})^{\frac{1}{3}} .
$$

The Prandtl number Pr in Equation (12) is replaced with the Schmidt number Sc,

$$
\mathrm{Sc}_{\mathrm{i}}(\mathrm{t})=\frac{\eta_{\mathrm{f}, \mathrm{i}}(\mathrm{t})}{\rho_{\mathrm{f}, \mathrm{i}}(\mathrm{t}) \cdot \mathrm{D}_{12, \mathrm{i}}(\mathrm{t})}
$$

For gases at low pressures, binary mass diffusivity $D_{12, \mathrm{i}}$ needed for the calculation of $S c_{\mathrm{i}}$ is estimated according to [26] with the following conditional equation:

$$
\mathrm{D}_{12, \mathrm{i}}(\mathrm{t})=\frac{1.43 \cdot 10^{-3} \cdot \mathrm{T}_{\mathrm{f}, \mathrm{i}}(\mathrm{t})^{1 \cdot 75} \cdot\left(\frac{1}{\mathrm{M}_{1}}+\frac{1}{\mathrm{M}_{2}}\right)^{\frac{1}{2}}}{\sqrt{2} \cdot \mathrm{p}_{\mathrm{f}, \mathrm{i}}(\mathrm{t}) \cdot\left[\left(\sum \Delta_{v 1}\right)^{\frac{1}{3}}+\left(\sum \Delta_{v 2}\right)^{\frac{1}{3}}\right]^{2}}
$$

where $M_{1}, M_{2}$ are the molar weights of substance 1 (solute) and 2 (solvent) accordingly; $p_{\mathrm{f}, \mathrm{i}}$ is the pressure of the fluid surrounding the particle; $\sum \Delta_{v 1}, \sum \Delta_{v 2}$ are diffusion volumes of substance 1 and 2 based on functional group contributions.

The individual gas-particle mass transfer coefficient $k_{\mathrm{i}}$ is derived from the Sherwood number obtained by Equation (15)

$$
\mathrm{k}_{\mathrm{i}}(\mathrm{t})=\frac{\mathrm{Sh}_{\mathrm{p}, \mathrm{i}}(\mathrm{t}) \cdot \mathrm{D}_{12, \mathrm{i}}(\mathrm{t})}{2 \cdot \mathrm{r}_{\mathrm{p}, \mathrm{i}}(\mathrm{t})} .
$$

The resulting mass flow $\dot{\mathrm{m}}_{\mathrm{vap}, \mathrm{i}}$ of vapor from the individual particle is described by Equation (19):

$$
\dot{\mathrm{m}}_{\mathrm{vap}, \mathrm{i}}(\mathrm{t})=\rho_{\mathrm{f}, \mathrm{i}}(\mathrm{t}) \cdot \mathrm{k}_{\mathrm{i}}(\mathrm{t}) \cdot 4 \pi \Delta \mathrm{r}_{\mathrm{p}, \mathrm{i}}(\mathrm{t})^{2} \cdot\left(\mathrm{Y}_{\mathrm{P}, \text { sat,i }}(\mathrm{t})-\mathrm{Y}_{\mathrm{f}, \mathrm{i}}(\mathrm{t})\right),
$$

where $Y_{\mathrm{P}, \text { sat,i }}$ and $Y_{\mathrm{f}, \mathrm{i}}$ are the time-dependent saturation humidity at the surface of each individual particle and of bulk fluid

$$
\mathrm{Y}_{\mathrm{P}, \text { sat }, \mathrm{i}}(\mathrm{t})=\frac{\mathrm{M}_{1}}{\mathrm{M}_{2}} \cdot \frac{\mathrm{p}_{\mathrm{vap}, \mathrm{i}}(\mathrm{t})}{\mathrm{p}_{\mathrm{f}, \mathrm{i}}(\mathrm{t})-\mathrm{p}_{\mathrm{vap}, \mathrm{i}}(\mathrm{t})}
$$

Here $p_{\mathrm{vap}, \mathrm{I}}$ is the vapor pressure for the evaporating substance at current temperature $T_{\mathrm{p}, \mathrm{i}}$ of each individual particle, calculated with Antoine's equation (Antoine coefficients $C_{A}, C_{B}$ and $C_{C}$ are listed in Table 3):

$$
\ln \mathrm{p}_{\mathrm{vap}, \mathrm{i}}(\mathrm{t})=\mathrm{C}_{\mathrm{A}}+\frac{\mathrm{C}_{\mathrm{B}}}{\mathrm{C}_{\mathrm{C}}+\mathrm{T}_{\mathrm{p}, \mathrm{i}}(\mathrm{t})}
$$


Table 3. Initial particle and material properties.

\begin{tabular}{|c|c|c|c|}
\hline Parameter & Symbol & Value & Unit \\
\hline \multicolumn{4}{|c|}{ initial particle properties } \\
\hline radius & $r_{p, 0}$ & $125 ; 250$ and 500 & $\mu \mathrm{m}$ \\
\hline solid weight fraction & $\mathrm{w}_{\mathrm{p}, \mathrm{S}, 0}$ & 0.4 & $\mathrm{~kg} / \mathrm{kg}$ \\
\hline temperature & $\mathrm{T}_{\mathrm{p}, 0}$ & 300 & K \\
\hline \multicolumn{4}{|c|}{ material properties of solid, liquid and gas } \\
\hline solid density & $\rho_{\mathrm{S}}$ & 2000 & $\mathrm{~kg} / \mathrm{m}^{3}$ \\
\hline liquid density & $\rho_{\mathrm{L}}$ & 1000 & $\mathrm{~kg} / \mathrm{m}^{3}$ \\
\hline solid heat capacity & $\mathrm{C}_{\mathrm{P}, \mathrm{S}}$ & 2500 & $\mathrm{~J} / \mathrm{kg} / \mathrm{K}$ \\
\hline liquid heat capacity & $\mathrm{C}_{\mathrm{P}, \mathrm{L}}$ & 4200 & $\mathrm{~J} / \mathrm{kg} / \mathrm{K}$ \\
\hline molecular weight of water & $\mathrm{M}_{\text {Water }}$ & 18.020 & $\mathrm{~g} / \mathrm{mol}$ \\
\hline molecular weight of pseudocomp. Air & $\mathrm{M}_{\text {Air }}$ & 28.949 & $\mathrm{~g} / \mathrm{mol}$ \\
\hline diffusion volume of water & $\sum \Delta_{v}$ Water & 13.1 & - \\
\hline diffusion volume of pseudocomp. Air & $\sum \Delta_{v \text { Air }}$ & 19.7 & - \\
\hline \multicolumn{4}{|c|}{ Antoine coefficients for $\mathrm{Pa}$ and $\mathrm{K}$} \\
\hline 1st; 2nd; 3rd Antoine coefficients & $\mathrm{C}_{\mathrm{A}} ; \mathrm{C}_{\mathrm{B}} ; \mathrm{C}_{\mathrm{C}}$ & $23.195 ;-3813.98 ;-46.29$ & - \\
\hline
\end{tabular}

The solids weight fraction $w_{\mathrm{p}, \mathrm{S}, \mathrm{i}}$ of the individual particles changes with time by the evaporation of the solvent and is described by:

$$
w_{p, S, i}(t+\Delta t)=w_{p, S, i}(t)+\frac{w_{p, S, i}(t) \cdot \dot{m}_{v a p, i}(t)}{m_{p, i}(t)} \cdot \Delta t .
$$

The evaporation of the solvent causes each individual particle to shrink and to change its mass. This transient behavior is described by Equations (23) and (24), where $\rho_{\mathrm{L}}$ is the density of the evaporated liquid:

$$
\begin{gathered}
\mathrm{r}_{\mathrm{p}, \mathrm{i}}(\mathrm{t}+\Delta \mathrm{t})=\mathrm{r}_{\mathrm{p}, \mathrm{i}}(\mathrm{t})-\frac{\dot{\mathrm{m}}_{\mathrm{vap}, \mathrm{i}}(\mathrm{t})}{\rho_{\mathrm{L}} \cdot 4 \pi \cdot \mathrm{r}_{\mathrm{p}, \mathrm{i}}(\mathrm{t})^{2}} \cdot \Delta \mathrm{t}, \\
m_{\mathrm{p}, \mathrm{i}}(\mathrm{t}+\Delta \mathrm{t})=m_{\mathrm{p}, \mathrm{i}}(t)-\dot{m}_{\mathrm{vap}, \mathrm{i}}(t) \cdot \Delta t .
\end{gathered}
$$

On the basis of the evaporated mass of liquid $\dot{\mathrm{m}}_{\mathrm{vap}, \mathrm{i}}$ the resulting enthalpy stream $\dot{\mathrm{H}}_{\mathrm{vap}, \mathrm{i}}$ from the gas to the liquid and vapor at the surface of each individual particle is calculated according to Equation (25), where $\Delta h_{\mathrm{vap}, \mathrm{i}}\left(T_{\mathrm{f}, \mathrm{i}}\right)$ is the temperature-dependent evaporation enthalpy of the liquid and $c_{\mathrm{P}, \mathrm{vap}, \mathrm{i}}$ is the specific heat capacity of the vapor at constant pressure:

$$
\dot{\mathrm{H}}_{\text {vap }, \mathrm{i}}(\mathrm{t})=\dot{\mathrm{m}}_{\mathrm{vap}, \mathrm{i}}(\mathrm{t}) \cdot\left(\Delta \mathrm{h}_{\mathrm{vap}, \mathrm{i}}\left(\mathrm{T}_{\mathrm{f}, \mathrm{i}}\right)+\mathrm{c}_{\mathrm{P}, \mathrm{vap}, \mathrm{i}} \cdot \mathrm{T}_{\mathrm{f}, \mathrm{i}}(\mathrm{t})\right) .
$$

The individual particle temperature $T_{\mathrm{p}, \mathrm{i}}$ is calculated as:

$$
\mathrm{T}_{\mathrm{p}, \mathrm{i}}(\mathrm{t}+\Delta \mathrm{t})=\mathrm{T}_{\mathrm{p}, \mathrm{i}}(\mathrm{t})+\frac{\dot{\mathrm{Q}}_{\mathrm{i}}(\mathrm{t})-\dot{\mathrm{H}}_{\mathrm{vap}, \mathrm{i}}(\mathrm{t})}{\mathrm{m}_{\mathrm{p}, \mathrm{i}}(\mathrm{t}+\Delta \mathrm{t}) \cdot \mathrm{c}_{\mathrm{P}, \mathrm{S}, \mathrm{i}}} \cdot \Delta \mathrm{t}
$$

\subsubsection{Calculation Algorithm}

The overall calculation algorithm for the particle modeling as discrete elements unilaterally coupled with CFD gas flow profiles is shown in Figure 3. At start of the simulation, flow profiles for all 10 time points are imported. This data is stored in RAM to increase the performance of data access. Afterwards, calculations are performed iteratively with a simulation time step $\Delta t$ until the end simulation time $t_{\text {end }}$. 


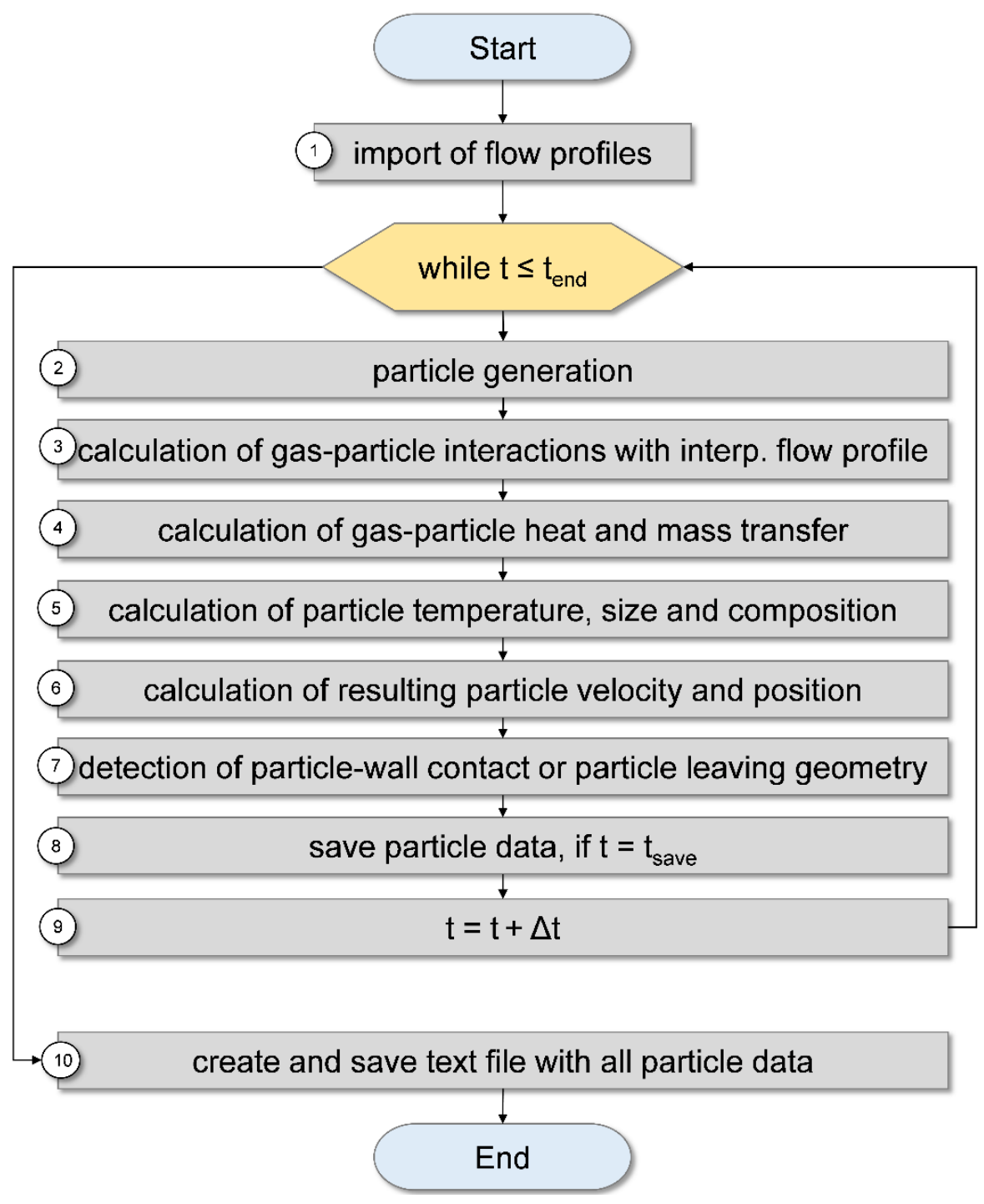

Figure 3. Calculation algorithm for discrete particle model.

In each simulation time step $\Delta t \cdot \dot{N}_{\mathrm{p}}$ new particles (droplets) are generated, where $\dot{N}_{\mathrm{p}}$ is the particle generation rate. Particles are generated in a point-like source $(x=0 ; y=0$ and $z=0.05)$ with an initial velocity in radial and vertical direction. The distribution of initial particle velocity is defined with a normal distribution. The parameters of the distribution are listed in Table 4. These parameters were chosen to cover all possible injection angles in a full cone with an opening angle of $30^{\circ}$, which is a typical spray cone geometry for this type of application. In the following algorithm stage, the forces acting on particles from the fluid are calculated. To obtain flow properties at a specific time point, linear interpolation of existing CFD data is performed. Gas particle interactions and resulting particle motion with respect to velocities, trajectories and positions are then calculated. On the basis of the resulting gas-particle heat and mass transfer new particle properties, such as temperature, solids weight fraction and particle size, are obtained. As a next step wall contacts or particles leaving the volume through the top are detected and correspondent elements are deactivated. Obtained information is saved into RAM with saving step $t_{\text {save }}$. The algorithm is repeated until the defined end time $t_{\text {end }}$ is reached. In the end, all data are saved to a text file. The format of saved text files is optimized for further analysis in the component-based framework MUSEN [27]. 
Table 4. Simulator settings.

\begin{tabular}{cccc}
\hline Parameter & Symbol & Value & Unit \\
\hline & time variables & & \\
simulation time step & $\Delta \mathrm{t}$ & $1.25 \times 10^{-4}$ & $\mathrm{~s}$ \\
end time & $\mathrm{t}_{\mathrm{end}}$ & 1 & $\mathrm{~s}$ \\
saving interval & $\mathrm{t}_{\mathrm{save}}$ & $6.25 \times 10^{-3}$ & $\mathrm{~s}$ \\
& particle generation variables & & \\
generation rate & $\dot{N}_{\mathrm{p}}$ & 40.000 & $1 / \mathrm{s}$ \\
generation origin & $\mathrm{x} ; \mathrm{y} ; \mathrm{z}$ & $0 ; 0 ; 0.05$ & $\mathrm{~m}$ \\
initial velocity mean/deviation & $\mathrm{v}_{\mathrm{x}}(0) ; \mathrm{v}_{\mathrm{y}}(0) ; \mathrm{v}_{\mathrm{z}}(0)$ & $0 / 0.1 ; 0 / 0.1 ; 0.5 / 0.2$ & $\mathrm{~m} / \mathrm{s}$ \\
\hline
\end{tabular}

\subsubsection{Parameters for Particle Simulation}

In this study, particles are composed of a model solid material and water as the solvent liquid. Besides a variation of particle size, all other parameters are kept constant for all simulation case studies. Table 3 lists all initial particle and material properties. Simulation time steps and saving intervals as well as the end time are kept constant for all simulation cases. To keep the computational effort and required storage space comparably low in all studies, one second of process time was simulated. The analysis of simulation results for longer time intervals such as 2 or 5 seconds shows that already after 1 second, a convergent solution is reached. The origin for particle generation was chosen to be in the center and slightly above the inlet cross section of the cylinder. The particle inlet velocity is set to be slow compared to the surrounding gas velocities. All simulation parameters and other boundary conditions are kept constant as well (see Table 4).

\section{Results}

The basis for particle simulation is obtained by CFD flow simulations. Therefore, the CFD simulation results will be outlined before the discussion of the resulting particle dynamics occurs.

\subsection{Fluid Flow Profile}

The variation of pulsation parameters results in different flow profiles obtained by CFD simulations. The sinusoidal velocity excitation at the inlet of the simulated volume leads to a transient oscillation that becomes stabilized after a certain simulation time. The duration of this start-up phase depends on the amplitude, frequency and acoustic response of the system. As shown in Figure 4, the time for stabilization is longer if the excitation is stronger, meaning higher amplitudes and frequencies.
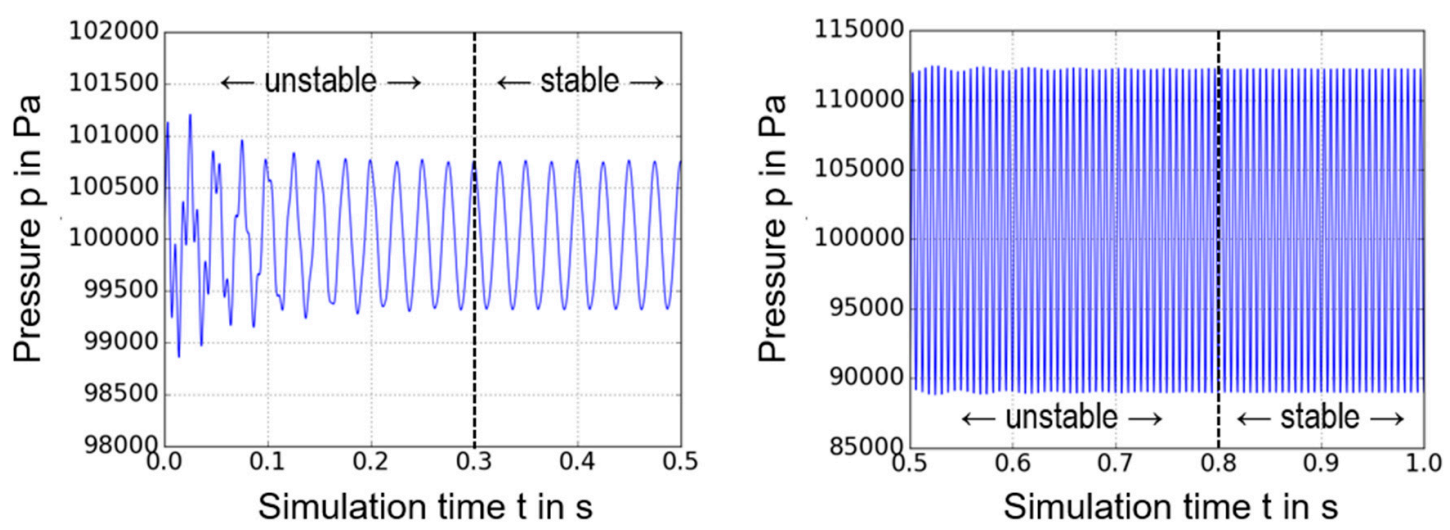

Figure 4. Stabilization time for two different simulation cases. Low excitation with stabilization after approximately $0.3 \mathrm{~s}$ (left) and high excitation with stabilization after approximately $0.8 \mathrm{~s}$ (right).

If the frequency of the excitation at the inlet is in resonance with the simulated volume, the response amplitudes of the pressure pulsation exceed the amplitudes of excitation (see $160 \mathrm{~Hz}$ in Figure 5). On the 
other hand, very low frequencies (in this case $40 \mathrm{~Hz}$ ) that are not in resonance with the simulated volume lead to a heavy damping of the resulting pressure amplitudes. At $80 \mathrm{~Hz}$, the response amplitude of the pressure pulsation is slightly damped and nearly of the same order as the amplitude of excitation. An exception can be observed for the lowest excitation amplitude at $80 \mathrm{~Hz}$. The response amplitude is heavily damped and is similar to the one of $40 \mathrm{~Hz}$.

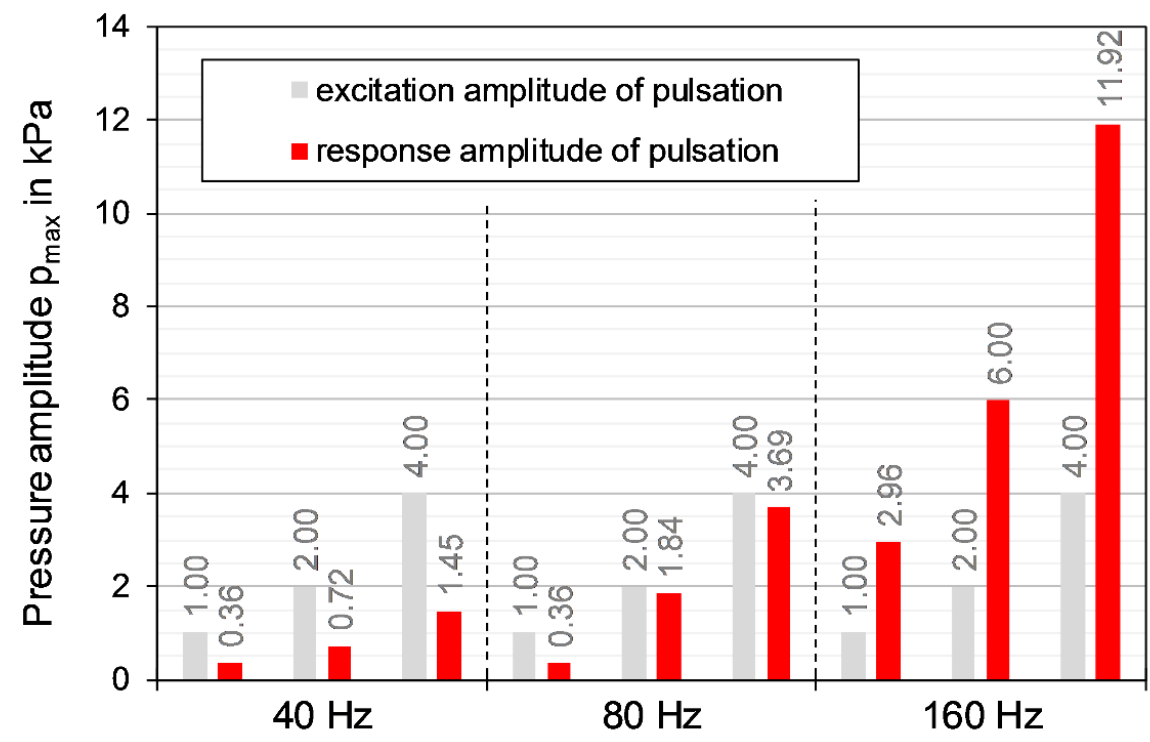

Figure 5. Response amplitudes of the pressure pulsation independent of frequency and amplitude of excitation.

Figure 6 shows different vertical flow velocity profiles over the cross section of the simulated volume. Compared to the stationary flow profile without pulsation ( $\hat{u}=0 \mathrm{~m} / \mathrm{s}$ ), the minimum and maximum vertical flow velocity profiles for one pulsation period are significantly changed. With increasing pulsation amplitude, the overall changes in velocity are intensified and-especially in the region close to the wall of the volume-the back flow is increased, with a bigger radial influence on the velocity profile.

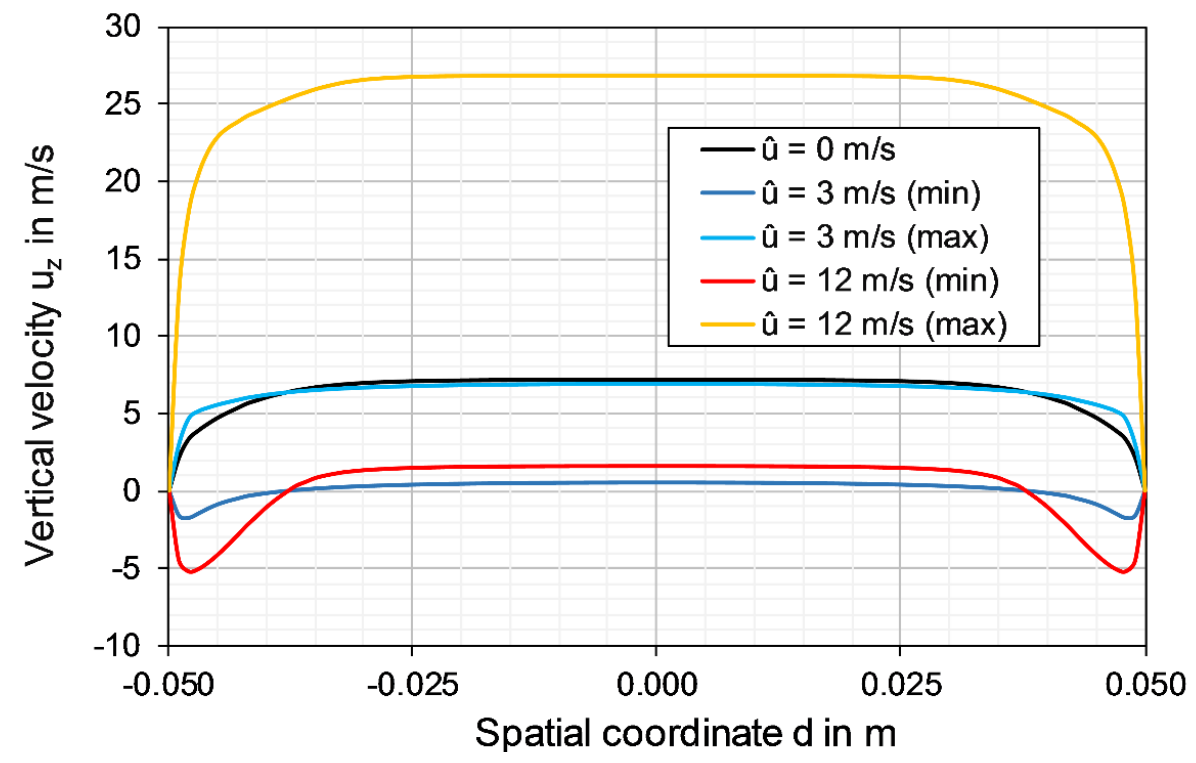

Figure 6. Cross-sectional computational fluids dynamic method (CFD) vertical minimum and maximum velocity profiles for different pulsation amplitudes at a pulsation frequency of $40 \mathrm{~Hz}$ and stationary flow $(\hat{\mathrm{u}}=0 \mathrm{~m} / \mathrm{s})$. 


\subsection{Behaviour of Solid Phase}

Based on the CFD simulations, particle simulations were carried out with parameter variations listed in Section 2.1. The simulations are evaluated with respect to particle dynamics, influencing the particle residence time $t_{\mathrm{R}}$ in the simulated volume and particle yield at the outlet of the volume, as well as with respect to gas-particle heat and mass transfer.

\subsubsection{Particle Dynamics}

The resulting particle dynamics for different flow conditions are shown in Figure 7 (low amplitude $3 \mathrm{~m} / \mathrm{s}$ ), Figure 8 (medium amplitude $6 \mathrm{~m} / \mathrm{s}$ ) and Figure 9 (high amplitude $12 \mathrm{~m} / \mathrm{s}$ ) for a simulation time point of $t_{\mathrm{sim}}=0.975 \mathrm{~s}$. The visualization of the simulation results was carried out with the component-based framework MUSEN [27].

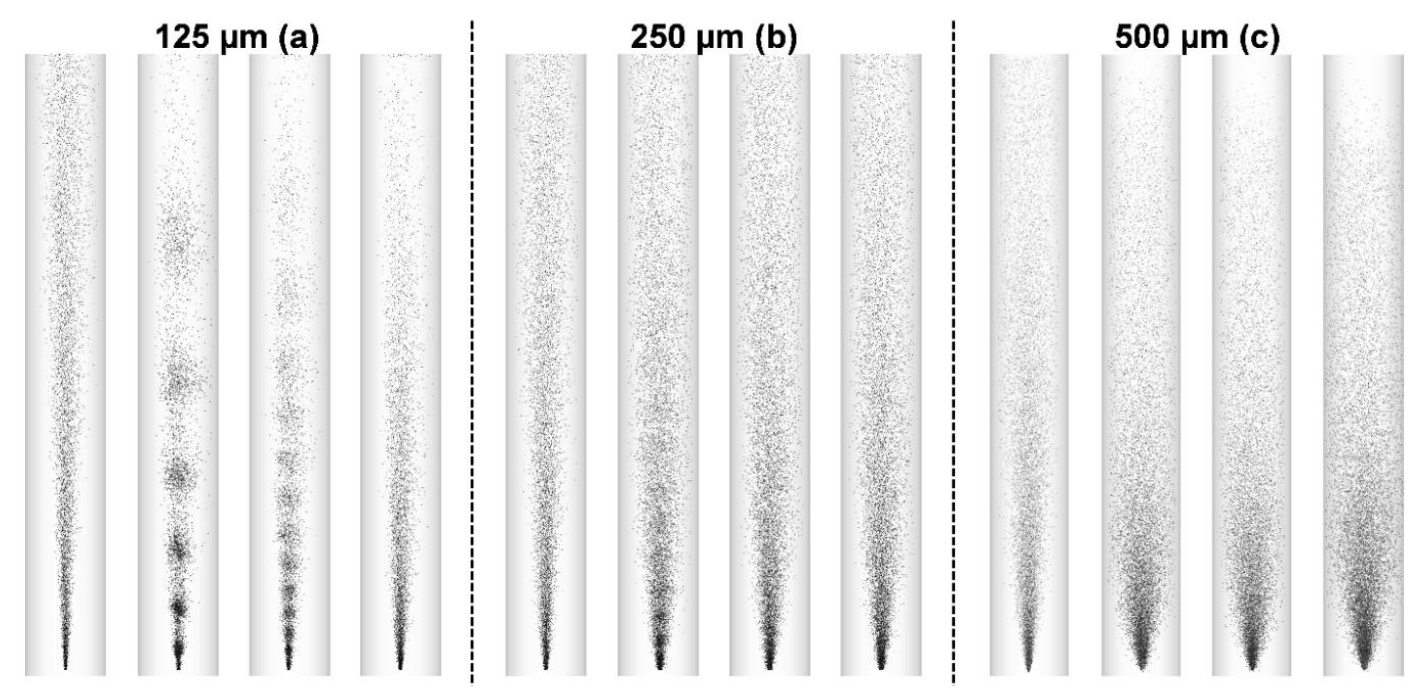

Figure 7. Particle dynamics and particle grouping effects independent of particle size (125 $\mu \mathrm{m}(\mathbf{a})$, $250 \mu \mathrm{m}(\mathbf{b})$ and $500 \mu \mathrm{m}$ (c)) as well as frequency (for each particle size from $0 \mathrm{~Hz}$ (left) to $160 \mathrm{~Hz}$ (right)) for a velocity pulsation amplitude of $\operatorname{umax}=3 \mathrm{~m} / \mathrm{s}$.

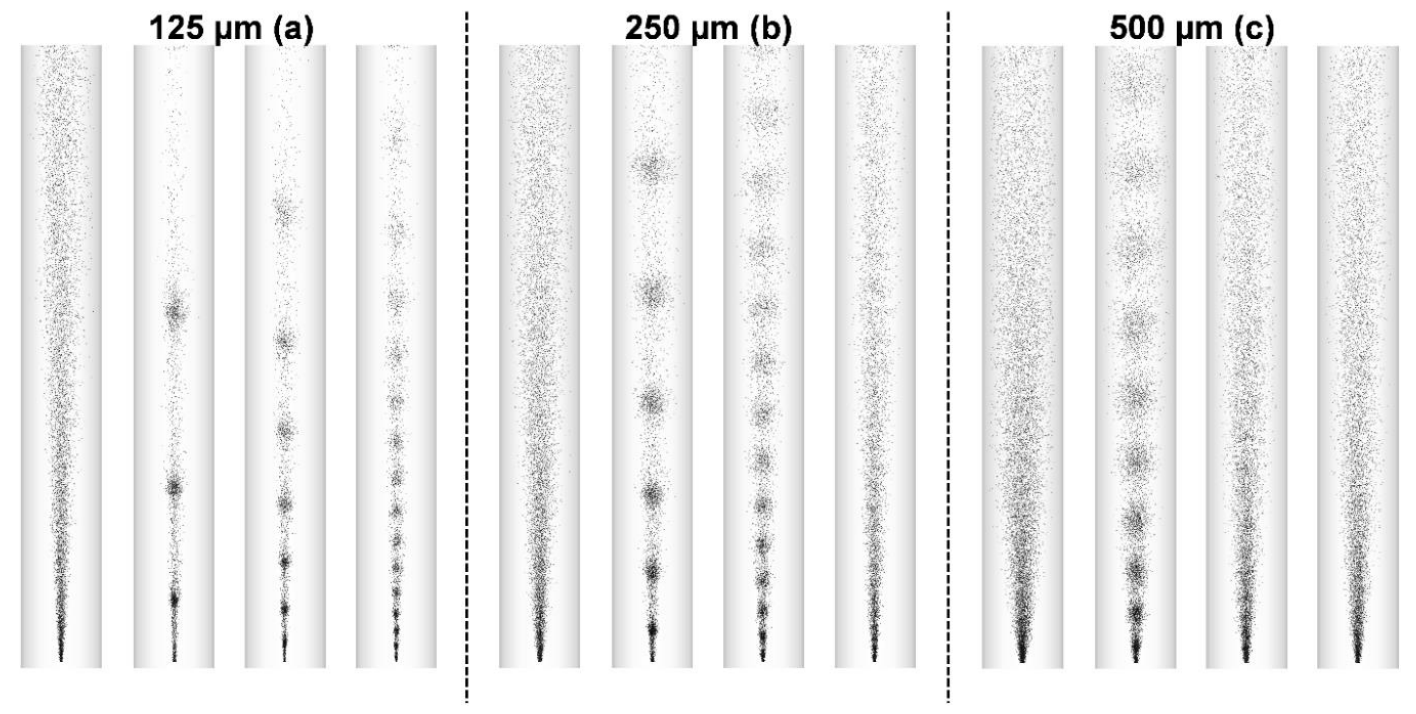

Figure 8. Particle dynamics and particle grouping effects independent of particle size (125 $\mu \mathrm{m}(\mathbf{a})$, $250 \mu \mathrm{m} \mathrm{(b)} \mathrm{and} 500 \mu \mathrm{m} \mathrm{(c))} \mathrm{as} \mathrm{well} \mathrm{as} \mathrm{frequency} \mathrm{(for} \mathrm{each} \mathrm{from} 0 \mathrm{~Hz}$ (left) to $160 \mathrm{~Hz}$ (right)) for a velocity pulsation amplitude of $u_{\max }=6 \mathrm{~m} / \mathrm{s}$. 


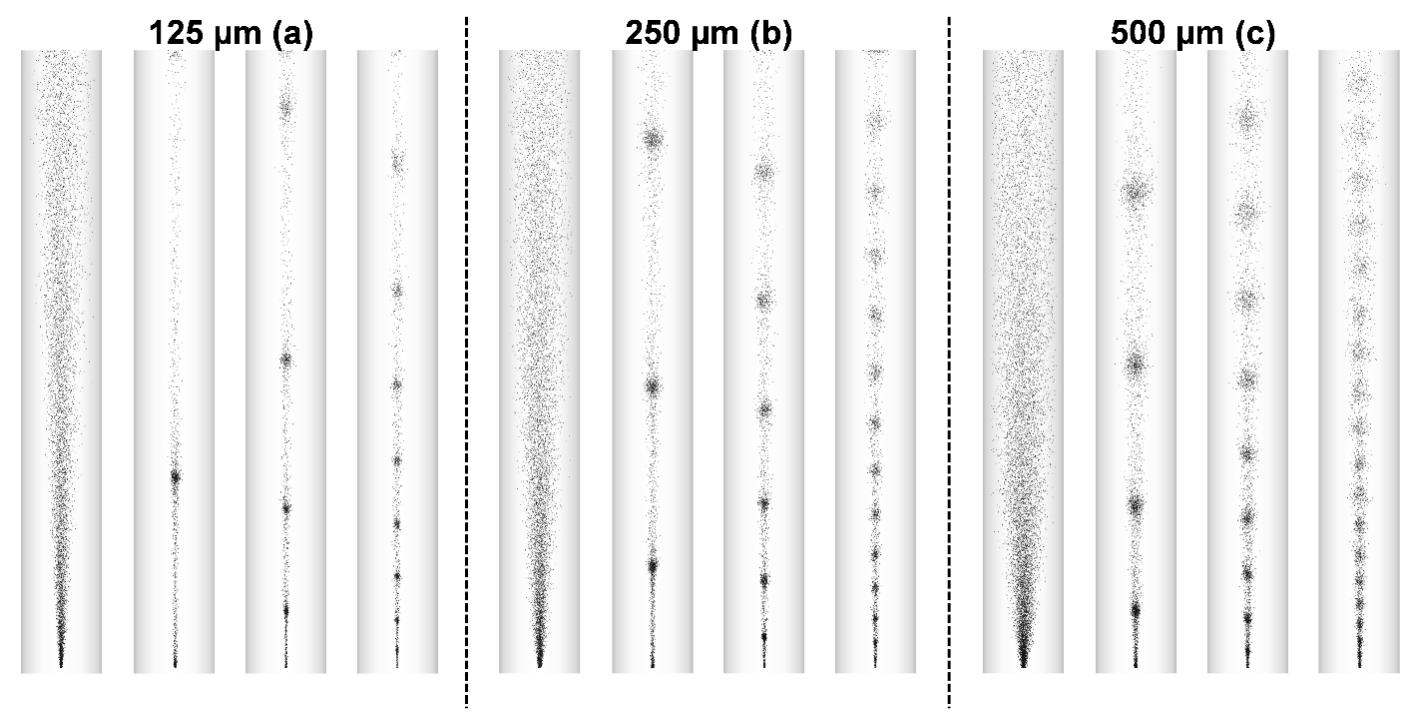

Figure 9. Particle dynamics and particle grouping effects independent of particle size (125 $\mu \mathrm{m}(\mathbf{a})$, $250 \mu \mathrm{m}(\mathbf{b})$ and $500 \mu \mathrm{m}(\mathbf{c})$ ) as well as frequency (for each from $0 \mathrm{~Hz}$ (left) to $160 \mathrm{~Hz}$ (right)) for a velocity pulsation amplitude of $u_{\max }=12 \mathrm{~m} / \mathrm{s}$.

Three different particle sizes (125 $\mu \mathrm{m}(\mathrm{a}), 250 \mu \mathrm{m}(\mathrm{b})$ and $500 \mu \mathrm{m}(\mathrm{c}))$ are shown in each figure. Each particle size is displayed for every four frequencies $(0 ; 40 ; 80$ and $160 \mathrm{~Hz})$. For better visibility during post-processing, all particle sizes were scaled to the biggest particle size with a radius of $500 \mu \mathrm{m}$. It can be observed that different particle grouping effects occur independent of particle size, pulsation amplitude and frequency. In general, the number of generated particle groups over the height of the simulated volume is increased by an increase of the pulsation frequency and particle size and a decrease of the pulsation amplitude.

At certain parameter combinations, e.g., for a frequency of 80 or $160 \mathrm{~Hz}$ in Figure $8 c$, the particle grouping cannot be visually identified. In these cases, the number of generated groups is high enough to blur the individual groups into a fully developed cone as seen in all stationary cases $(0 \mathrm{~Hz})$, where definitely no particle groups can be present. Particle grouping can be traced back to continuous particle injection with a given initial injection speed in a non-stationary flow field. Particles injected during the acceleration phase (positive velocity amplitude in z-direction of one oscillation period) will have a higher transport velocity at the time of injection than particles injected during the deceleration phase (negative velocity amplitude in z-direction of the same oscillation period). This effect in the starting phase of the transport is directly influenced by the amplitude and frequency, which can be seen as the intensity and duration of deflection, and the particle size, which defines the mass inertia. This explains why groups of big particles are closer to each other than groups of small particles at otherwise same conditions.

Groups of the same particle size are further away from each other at higher amplitudes and closer together for increased frequencies at otherwise constant conditions.

Furthermore, in comparison with the stationary flow, it can be seen that the geometry of the particle spout is constricted with pulsation velocity amplitudes higher than the mean flow velocity (Figures 8 and 9) and widened with pulsation velocity amplitudes lower than the mean flow velocity of the gas (Figure 7). This effect is further influenced by the consideration of larger particle sizes. In the case of Figure 7, on the right (c), it is clearly visible that particles with a radius of $500 \mu \mathrm{m}$ are not properly transported out of the simulated volume. The widening and constriction as well as an insufficient pneumatic transport of the particles has an effect on the particle yield. 


\subsubsection{Particle Yield}

Particle yield is defined as the fraction of particles having left the simulated volume over the defined outlet. Moreover, the fraction of individual particles that have experienced a wall contact is analyzed. It is assumed that all particles that are not completely dried and become in contact with the wall of the geometry will stick to it as a worst-case scenario. Their last data of activity is saved. From that point on, they will not be considered for further simulation time steps.

Figure 10 shows the results for particle yield or loss considerations as the fraction of particles having left the volume through its outlet (yield) and the fraction of particles having experienced a wall contact (loss). It can be seen that the particle yield is influenced with the variation of the pulsation parameters. Compared to stationary flow, the particle yield is enhanced for all frequencies at medium $(6 \mathrm{~m} / \mathrm{s})$ and high $(12 \mathrm{~m} / \mathrm{s})$ pulsation velocity amplitudes. For the medium amplitude, the yield for the biggest particle size with a radius of $500 \mu \mathrm{m}$ is roughly 0.83 for all frequencies, whereas the yield for the lowest particle size with a particle radius of $125 \mu \mathrm{m}$ is 0.98 and higher for all frequencies. Compared to an amplitude of $6 \mathrm{~m} / \mathrm{s}$, an amplitude of $12 \mathrm{~m} / \mathrm{s}$ results in a yield of 0.98 and above for all particle sizes. For low $(3 \mathrm{~m} / \mathrm{s})$ pulsation velocity amplitudes an enhancement can only be observed for the smallest particle size. For the biggest particle size almost all particles experience a wall contact leading to a particle yield going close to zero. This can be linked to the findings in the section of particle dynamics. For these cases, a widening of the spout can be observed, which enhances the chances of a wall collision and, furthermore, the insufficient pneumatic transport of particles occurs.

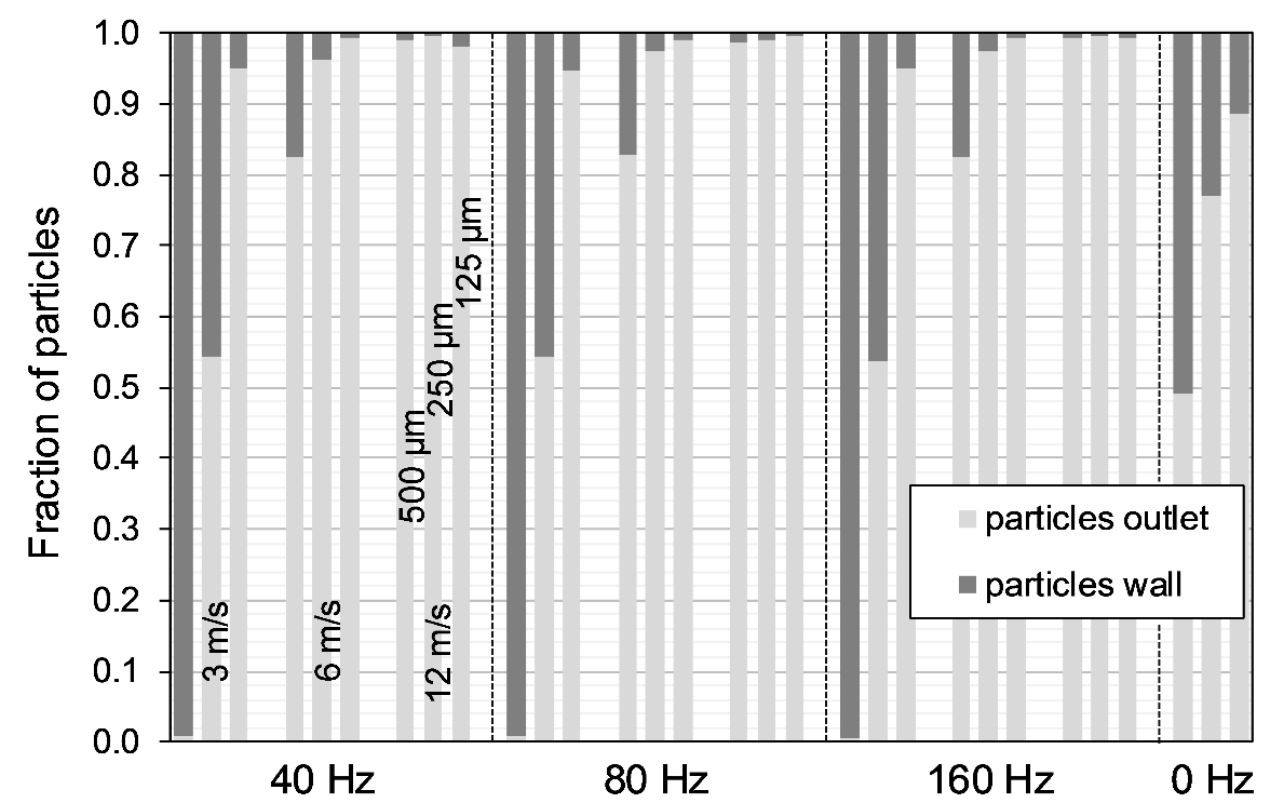

Figure 10. Comparison of particle yield and loss for all different simulation cases independent of initial particle size $(125 ; 250$ and $500 \mu \mathrm{m})$, pulsation frequency $(0 ; 40 ; 80$ and $160 \mathrm{~Hz})$ and pulsation velocity amplitude $(0 ; 3 ; 6$ and $12 \mathrm{~m} / \mathrm{s})$.

\subsubsection{Mean Particle Residence Time and Gas-Particle Heat and Mass Transfer}

Particle properties, such as particle temperature $T_{\mathrm{p}}$ and particle solids mass fraction $w_{\mathrm{p}, \mathrm{S}}$ at the outlet of the simulation domain are influenced by predominating heat and mass transfer in combination with the mean residence time $t_{\mathrm{R}}$ resulting from different pulsation parameters. Figure 11 shows the normalized mean heat transfer coefficient $h_{\text {norm }}$ for two different pulsation frequencies in relation to initial particle radius and pulsation flow velocity amplitude. Mean heat transfer coefficients are normalized to the values of stationary gas flow, which also gives information about the heat transfer enhancement factor. An increase of the pulsation velocity amplitude enhances the heat transfer compared to stationary gas flow, except for the cases that have insufficient pneumatic transport. 
Comparing the minimum and maximum frequency shows a negligible influence on the mean heat transfer enhancement. The maximum enhancement factor for $40 \mathrm{~Hz}$ is 1.395 compared to 1.386 for $160 \mathrm{~Hz}$ at otherwise same conditions. Neglecting the insufficient pneumatic transport of bigger particles for the discussed cases, the overall range of heat transfer enhancement is in-between 1.063 and 1.395, where a higher enhancement can be observed for smaller particles. Because of the analogy between heat and mass transfer, mass transfer results will not be further discussed at this point.
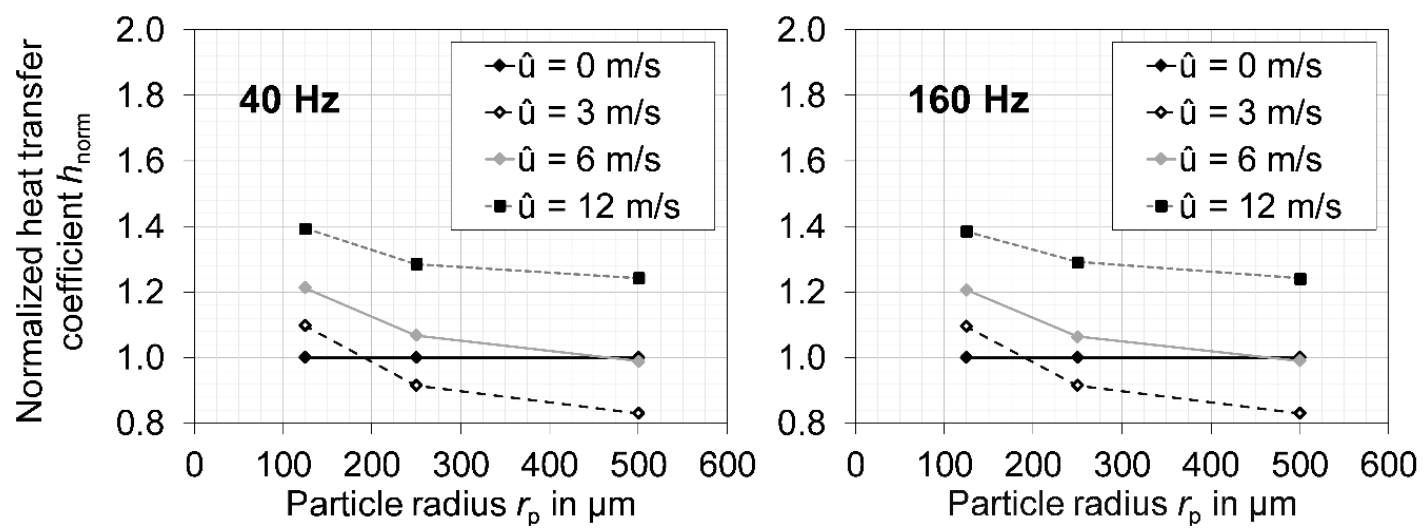

Figure 11. Normalized mean heat transfer coefficients $h_{\text {norm }}$ for pulsation frequencies of $40 \mathrm{~Hz}$ (left) and $160 \mathrm{~Hz}$ (right) independent of initial particle size $r_{\mathrm{p}, 0}$ and pulsation flow velocity amplitude $\hat{u}$.

Table 5 shows the correlation between resulting residence times and mean particle temperatures as well as mean particle solids mass fraction independent of varied pulsation parameters and particle size. Taking a closer look at the mean residence times for different particle sizes, a reduction of the mean residence time can be observed with an increase of the pulsation amplitude compared to the stationary gas flow. In equal measure, pulsation frequency has a negligible influence on the same. As discussed in Section 3.2.1, the insufficient pneumatic transport of coarser particles ( $250 \mu \mathrm{m}$ and $500 \mu \mathrm{m}$ ) can also be observed in terms of prolonged mean residence times for the lowest pulsation velocity amplitude. In terms of temperature $T_{\mathrm{p}}$, a clear differentiation can be observed for the largest particles at the highest velocity pulsation amplitude. All other mean particle temperatures at the outlet of the simulated cylindrical volume are in the range of $340.1-341.8 \mathrm{~K}$, whereas the mean outlet temperature of the other cases' particles is as low as approximately $333.3 \mathrm{~K}$.

Table 5. Mean particle properties and residence times at the outlet of the simulated volume independent of initial particle size and gas pulsation parameters.

\begin{tabular}{|c|c|c|c|c|c|c|c|c|c|c|}
\hline \multirow[t]{3}{*}{$f_{\text {puls }}$} & \multirow[t]{3}{*}{$u_{\max }$} & \multicolumn{9}{|c|}{$r_{\mathrm{p}}(\mathrm{t}=0)$} \\
\hline & & \multicolumn{3}{|c|}{$125 \mu \mathrm{m}$} & \multicolumn{3}{|c|}{$250 \mu \mathrm{m}$} & \multicolumn{3}{|c|}{$500 \mu \mathrm{m}$} \\
\hline & & $t_{\mathrm{R}}$ in $\mathrm{ms}$ & $T_{\mathrm{p}}$ in $\mathrm{K}$ & $w_{p, S}$ in $g / k g$ & $t_{\mathrm{R}}$ in $\mathrm{ms}$ & $T_{\mathrm{p}}$ in $\mathrm{K}$ & $w_{p, S}$ in $g / k g$ & $t_{\mathrm{R}}$ in $\mathrm{ms}$ & $T_{\mathrm{p}}$ in $\mathrm{K}$ & $\mathrm{w}_{\mathrm{p}, \mathrm{S}}$ in $\mathrm{g} / \mathrm{kg}$ \\
\hline $0 \mathrm{~Hz}$ & $0 \mathrm{~m} / \mathrm{s}$ & 213 & 341.2 & 894 & 280 & 341.4 & 522 & 398 & 341.4 & 440 \\
\hline \multirow{3}{*}{$40 \mathrm{~Hz}$} & $3 \mathrm{~m} / \mathrm{s}$ & 175 & 341.6 & 837 & 410 & 341.4 & 591 & 946 & 341.5 & 513 \\
\hline & $6 \mathrm{~m} / \mathrm{s}$ & 100 & 341.6 & 616 & 179 & 341.5 & 473 & 269 & 340.1 & 420 \\
\hline & $12 \mathrm{~m} / \mathrm{s}$ & 55 & 341.7 & 513 & 90 & 341.3 & 434 & 126 & 333.3 & 407 \\
\hline \multirow{3}{*}{$80 \mathrm{~Hz}$} & $3 \mathrm{~m} / \mathrm{s}$ & 175 & 341.6 & 837 & 410 & 341.4 & 592 & 943 & 341.5 & 513 \\
\hline & $6 \mathrm{~m} / \mathrm{s}$ & 101 & 341.6 & 616 & 179 & 341.5 & 473 & 269 & 340.1 & 420 \\
\hline & $12 \mathrm{~m} / \mathrm{s}$ & 56 & 341.8 & 514 & 90 & 341.3 & 434 & 126 & 333.3 & 407 \\
\hline \multirow{3}{*}{$160 \mathrm{~Hz}$} & $3 \mathrm{~m} / \mathrm{s}$ & 175 & 341.6 & 838 & 410 & 341.4 & 592 & 946 & 341.5 & 513 \\
\hline & $6 \mathrm{~m} / \mathrm{s}$ & 101 & 341.6 & 616 & 179 & 341.4 & 473 & 269 & 340.1 & 420 \\
\hline & $12 \mathrm{~m} / \mathrm{s}$ & 56 & 341.7 & 515 & 90 & 341.2 & 434 & 126 & 333.3 & 407 \\
\hline
\end{tabular}

Even though the mean heat and mass transfer coefficient for these cases is higher compared to the other cases and the mean residence time is more than two-times longer than for the smallest particle, the larger particle size and associated increase of volume and mass to the power of 3 cannot 
be compensated. This correlation can also be seen for the solids mass fraction $w_{\mathrm{p}, \mathrm{S}}$ of the particles. In terms of this solid mass fraction of the particles at the outlet of the simulated volume, a bigger influence can be observed. By neglecting simulation cases with insufficient pneumatic transport, a clear and obvious trend for the solid mass fraction can be identified. The bigger the particle and the shorter the residence time, the lower the resulting solid mass fraction at the outlet of the simulated volume will be with increased velocity pulsation amplitude.

\subsubsection{Residence Time Distribution}

Particle dynamics resulting from different pulsation parameters and concomitant particle residence time distributions have an influence on the homogeneity of particle properties at the outlet of the simulated cylindrical volume. Figures 12-14 show resulting particle residence time distributions as number-density distributions $\mathrm{q}_{0}$ for different initial particle sizes independent of pulsation parameters.
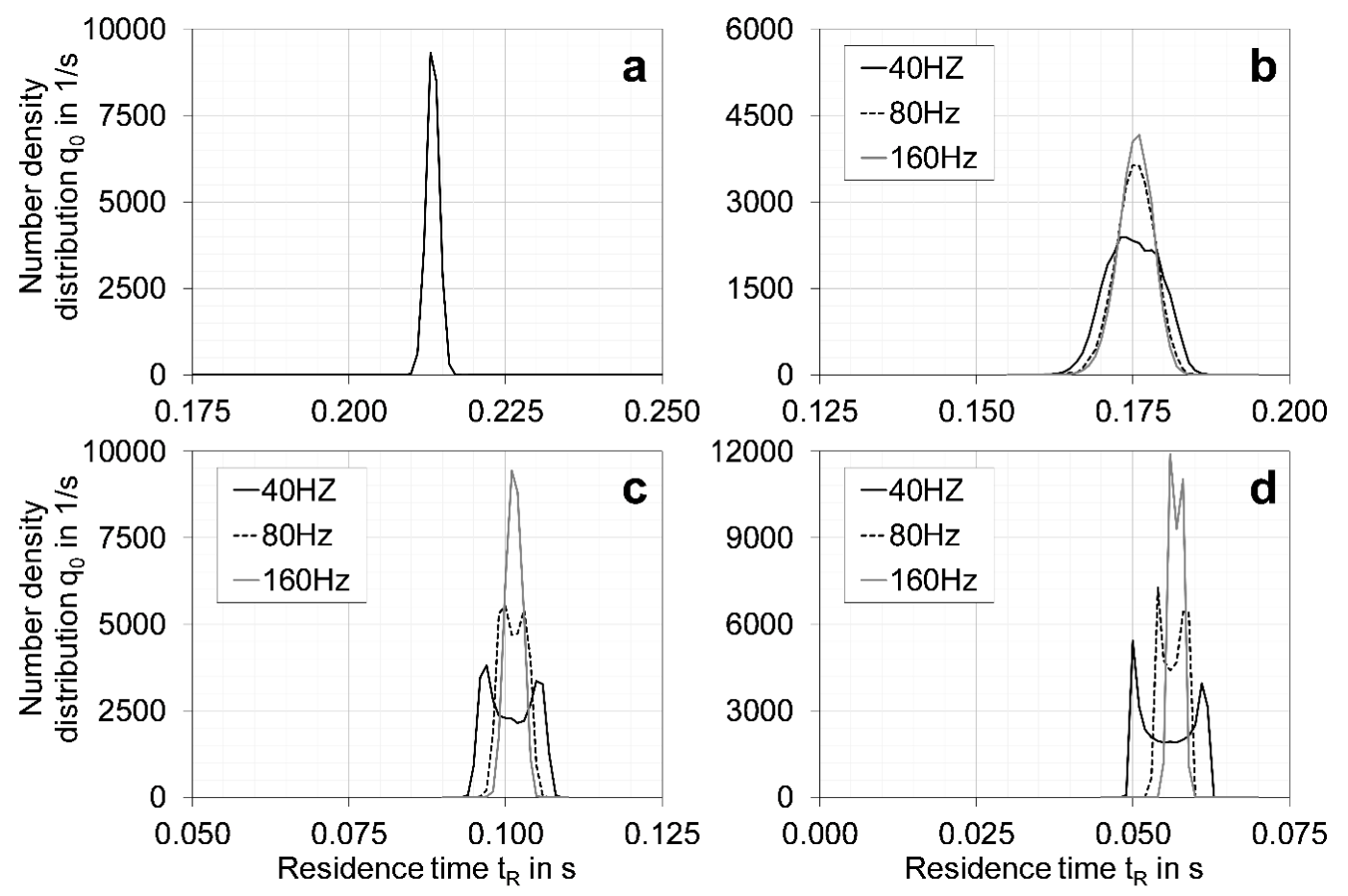

Figure 12. Number density distributions $q_{0}$ for particle residence times with an initial particle radius $r_{\mathrm{p}, 0}$ of $125 \mu \mathrm{m}$ and (a) stationary flow, (b) velocity pulsation amplitude of $u_{\max }=3 \mathrm{~m} / \mathrm{s}$, (c) velocity pulsation amplitude of $u_{\max }=6 \mathrm{~m} / \mathrm{s}$ and (d) pulsation amplitude of $u_{\max }=12 \mathrm{~m} / \mathrm{s}$.

The width of each residence time class is chosen to be 1 millisecond. Figure 12 shows the resulting residence time distributions for an initial particle radius $r_{p, 0}$ of $125 \mu \mathrm{m}$. Particle residence times for stationary flow (a) are characterized by a narrow monomodal distribution with a distribution width of $9 \mathrm{~ms}$. A pulsation amplitude of $3 \mathrm{~m} / \mathrm{s} \mathrm{(b)} \mathrm{also} \mathrm{shows} \mathrm{monomodal} \mathrm{residence} \mathrm{time} \mathrm{distributions} \mathrm{for}$ pulsation frequencies of 80 and $160 \mathrm{~Hz}$ but compared to (a) with wider distribution widths of 22 and $24 \mathrm{~ms}$. At a pulsation frequency of $40 \mathrm{~Hz}$, the residence time distribution is the widest with a distribution width of $30 \mathrm{~ms}$ and does not show a clear monomodal shape. Compared with a pulsation amplitude of $6 \mathrm{~m} / \mathrm{s}$ (c), a frequency of $40 \mathrm{~Hz}$ at $\mathrm{u}_{\max }=3 \mathrm{~m} / \mathrm{s}$ indicates the development of bimodal distributions under pulsating conditions. At a pulsation amplitude of $6 \mathrm{~m} / \mathrm{s}$, bimodal residence time distributions are generated by pulsation frequencies of 40 and $80 \mathrm{~Hz}$ with distribution widths of 17 and $12 \mathrm{~ms}$. A pulsation frequency of $160 \mathrm{~Hz}$ results in a monomodal distribution with a distribution width of $10 \mathrm{~ms}$. The highest velocity pulsation amplitude of $12 \mathrm{~m} / \mathrm{s}$ (d) shows bimodal residence time distributions for all investigated frequencies. The resulting distribution widths are $15 \mathrm{~ms}$ for $f_{\text {puls }}=40 \mathrm{~Hz}, 9 \mathrm{~ms}$ for $f_{\text {puls }}=80 \mathrm{~Hz}$ and $6 \mathrm{~ms}$ for $f_{\text {puls }}=160 \mathrm{~Hz}$. Compared to stationary flow (a) 
only pulsation parameter combinations of an amplitude of $12 \mathrm{~m} / \mathrm{s}$ and pulsation frequencies of 80 and $160 \mathrm{~Hz}$ indicate equal or higher homogeneity for the product particles obtained at the outlet of the simulated volume due to the lower width of residence time distributions.
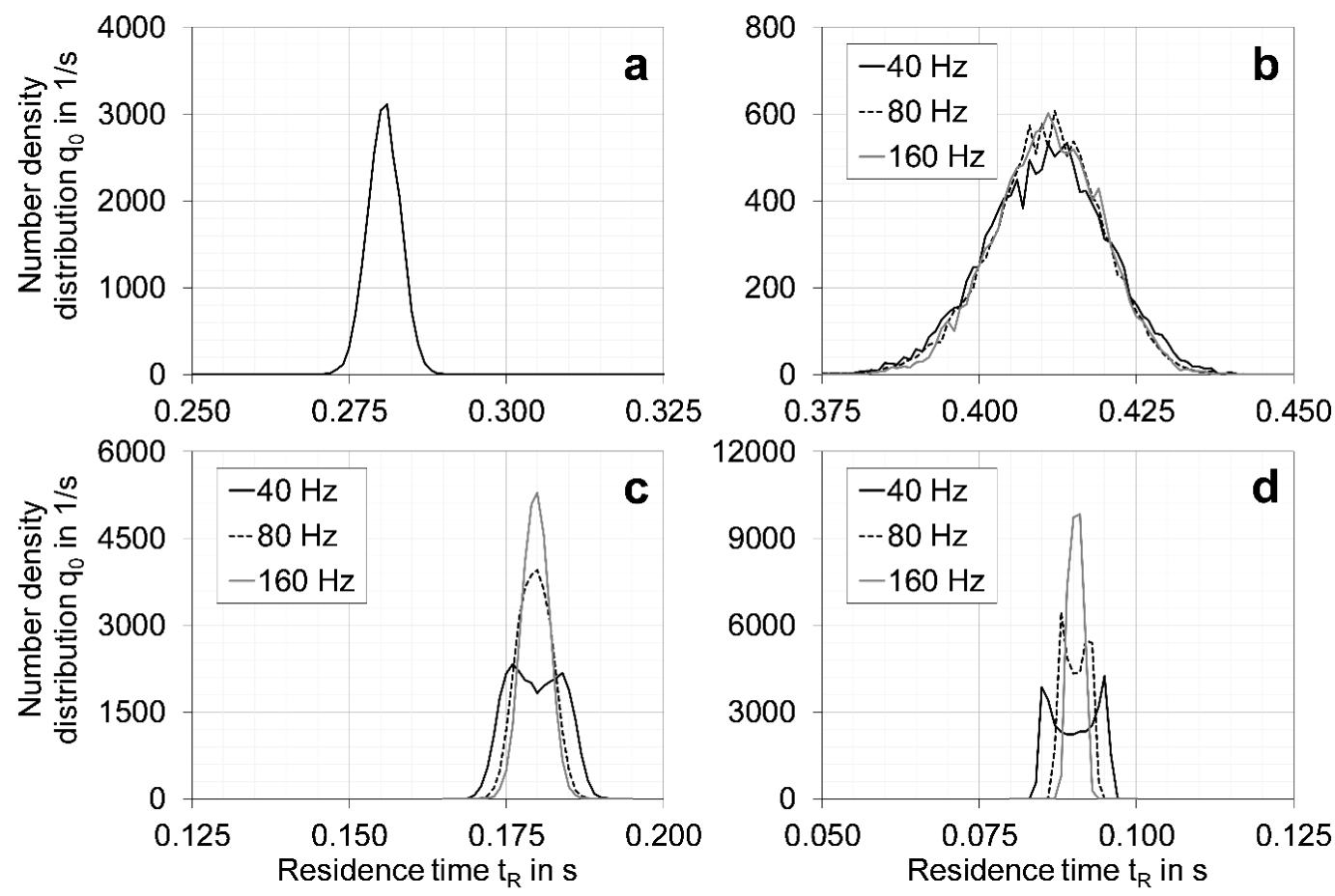

Figure 13. Number density distributions $\mathrm{q}_{0}$ for particle residence times with an initial particle radius $r_{p, 0}$ of $250 \mu \mathrm{m}$ and (a) stationary flow, (b) velocity pulsation amplitude of $u_{\max }=3 \mathrm{~m} / \mathrm{s}$, (c) velocity pulsation amplitude of $u_{\max }=6 \mathrm{~m} / \mathrm{s}$ and $(\mathbf{d})$ velocity pulsation amplitude of $\mathrm{u}_{\max }=12 \mathrm{~m} / \mathrm{s}$.
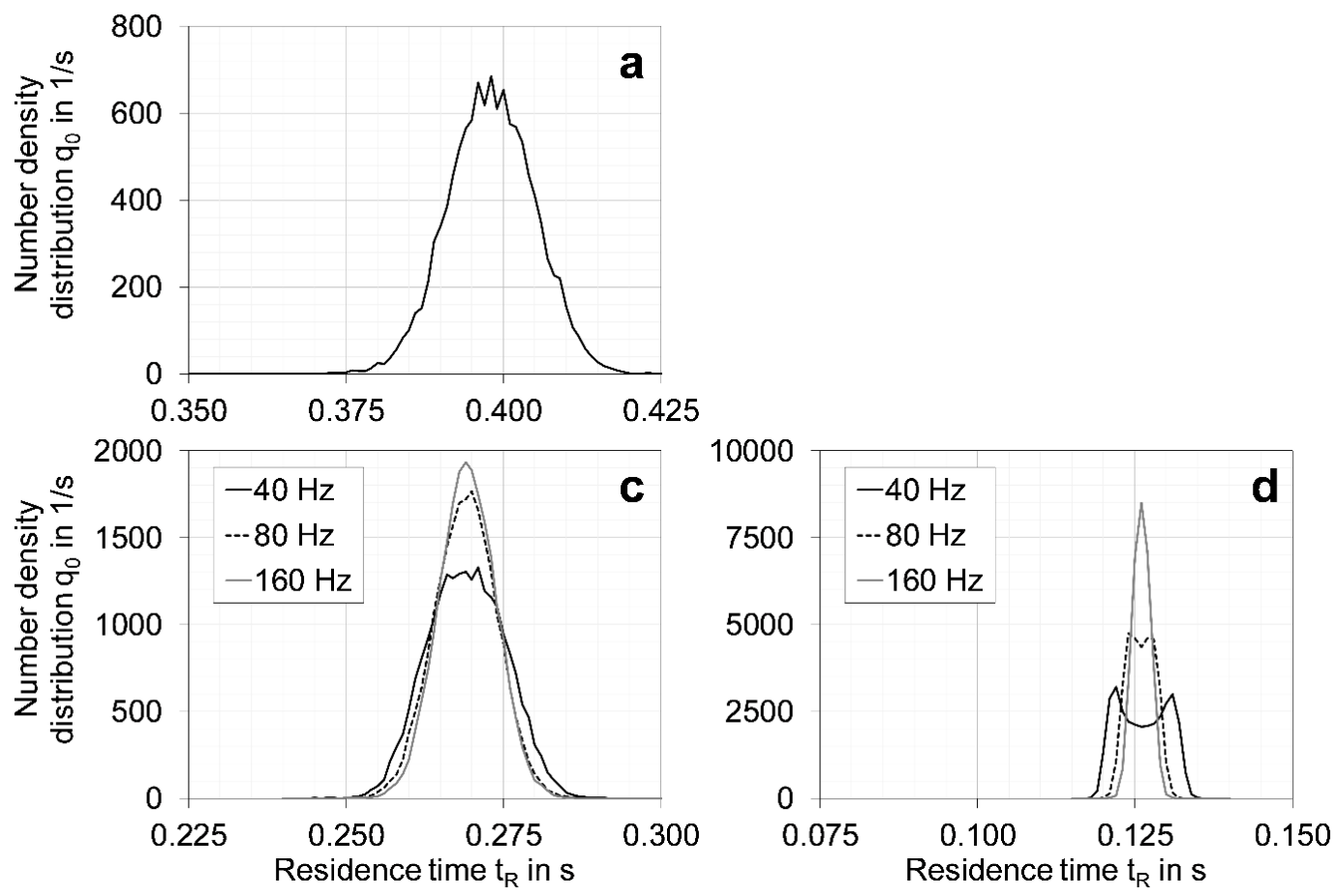

Figure 14. Number density distributions $q_{0}$ for particle residence times with an initial particle radius $r_{\mathrm{p}, 0}$ of $250 \mu \mathrm{m}$ and (a) stationary flow, (c) velocity pulsation amplitude of $u_{\max }=6 \mathrm{~m} / \mathrm{s}$ and (d) velocity pulsation amplitude of $u_{\max }=12 \mathrm{~m} / \mathrm{s}$. 
Figure 13 shows resulting residence time distributions for an initial particle radius of $250 \mu \mathrm{m}$. Similar to Figure 12, particle residence times for stationary flow (a) are characterized by a narrow monomodal distribution with a distribution width of $21 \mathrm{~ms}$. Comparing (a) in Figure 13 to (a) in Figure 12, the residence time distribution for particles at the outlet of the simulated volume is wider. Insufficient pneumatic transport at a low velocity pulsation amplitude of $3 \mathrm{~m} / \mathrm{s}$ for all investigated frequencies with an initial radius of $250 \mu \mathrm{m}$ can also be detected in the residence time distributions (b). As discussed in Section 3.2.1, for these simulation cases, the mean residence time is prolonged. The distribution curves appear "spiky" and the widths are the widest between 63 and $71 \mathrm{~ms}$. At a pulsation amplitude of $6 \mathrm{~m} / \mathrm{s}$ (c) in Figure 13a bimodal residence time distribution is generated by a pulsation frequency of $40 \mathrm{~Hz}$ with a distribution width of $24 \mathrm{~ms}$. Compared to the obtained bimodal residence time distribution for particles with the smallest investigated initial radius in (c) of Figure 12, a pulsation frequency of $80 \mathrm{~Hz}$ for medium-sized particles results in a monomodal residence time distribution with a distribution width of $21 \mathrm{~ms}$. The distribution width of monomodal distributed residence times at $160 \mathrm{~Hz}$ is $0.019 \mathrm{~ms}$. The highest pulsation amplitude $u_{\max }=12 \mathrm{~m} / \mathrm{s}$ (d) only shows bimodal residence time distributions for frequencies of 40 and $80 \mathrm{~Hz}$. The resulting distribution widths are $16 \mathrm{~ms}$ for $40 \mathrm{~Hz}, 1 \mathrm{~ms}$ for $80 \mathrm{~Hz}$ and $7 \mathrm{~ms}$ for $160 \mathrm{~Hz}$, whereas the narrowest distribution is of monomodal shape. Compared to stationary flow (a), only pulsation parameter combinations of an amplitude $6 \mathrm{~m} / \mathrm{s}$ and pulsation frequencies 80 and $160 \mathrm{~Hz}$, as well as an amplitude $12 \mathrm{~m} / \mathrm{s}$ at all pulsation frequencies, indicate equal or higher homogeneity for the product particles obtained at the outlet of the simulated volume. Figure 14 shows resulting residence time distributions for the biggest investigated initial particle radius of $500 \mu \mathrm{m}$. Due to the insufficient pneumatic transport, for the lowest pulsation amplitude $u_{\max }=3 \mathrm{~m} / \mathrm{s}$, particle residence time distributions could not be evaluated. Therefore, Figure 14 only shows results for the cases of stationary flow, as well as medium and maximum investigated pulsation amplitude. Compared to Figures 12 and 13, particle residence times for stationary flow (a) are not characterized by a narrow monomodal distribution. The distribution width is $50 \mathrm{~ms}$ and is also the highest of all cases for the biggest particles. A pulsation amplitude of $6 \mathrm{~m} / \mathrm{s}$ (c) shows monomodal residence time distributions for pulsation frequencies of 80 and $160 \mathrm{~Hz}$ and compared to stationary flow (a) with narrower distribution widths of 41 and $38 \mathrm{~ms}$. At a pulsation frequency of $40 \mathrm{~Hz}$, the residence time distribution does not show a clear monomodal shape. The distribution width is $48 \mathrm{~ms}$ and is still lower than the width for the stationary flow.

For the highest investigated pulsation amplitude of $12 \mathrm{~m} / \mathrm{s}(\mathrm{d})$, bimodal residence time distributions are found for frequencies of $f_{\text {puls }}=40$ and $80 \mathrm{~Hz}$ and a monomodal residence time distribution is found for $160 \mathrm{~Hz}$. The resulting distribution widths are $20 \mathrm{~ms}$ for frequency $40 \mathrm{~Hz}, 14 \mathrm{~ms}$ for $80 \mathrm{~Hz}$ and $12 \mathrm{~ms}$ for $160 \mathrm{~Hz}$. Generally, all cases with medium (c) and maximum (d) investigated pulsation amplitudes deliver higher product-particle homogeneity compared to stationary flow (a).

The generation of bimodal residence time distributions can be linked to the formation of particle groups as discussed in Section 3.2.1. Particles are continuously injected at different times of the overlying non-stationary pulsation of the gas flow. Particles injected during the acceleration phase (positive velocity amplitude in z-direction of one oscillation period) will have a shorter residence time than particles injected during the deceleration phase (negative velocity amplitude in z-direction of the same oscillation period). This leads to the formation of two main groups of particles (accelerated and decelerated at the point of injection), which can be detected in a bimodal residence time distribution. Essentially, this leads to the assumption that all pulsating cases would result in bimodal distributed residence times of particles in the simulated volume. As pointed out in Section 3.2.1, at certain parameter combinations, the number of groups blur into a continuous flow, where the individual particle groups cannot be identified anymore.

\section{Discussion}

In this contribution, CFD simulations combined with discrete particle simulations were used to investigate gas-particle micro-processes in pulsed gas-solid multiphase flows. On the basis of typical 
operating parameters of Glatt's APPtec ${ }^{\circledR}$ method, parameters for variation of pulsation amplitude and frequency were selected and pulsed gas flow-induced single particle dynamics as well as the resulting gas-particle heat and mass transfer was derived for three exemplary particle sizes.

In comparison to stationary gas flow, an enhancement of heat and mass transfer could be identified with the increase of the pulsation amplitude and a decrease of particle size. Enhancement factors vary between 1.1 and 1.4. Furthermore, it was found that particle yield, grouping effects and particle residence time in the simulated volume can be influenced by the adjustment of pulsation parameters. The most influencing parameter was identified to be the amplitude of the pulsation. For pulsation amplitudes lower than the mean gas flow velocity, mean particle residence times are extended compared to the stationary flow case, and additionally the yield decreases because of a higher number of wall contacts. Higher pulsation amplitudes than the mean gas flow velocity result in a shortening of particle residence times and an increase of the particle yield.

Pulsation frequency of the excitation plays a minor role, when looking at mean values of heat and mass transfer as well as particle residence time. By evaluating the distributed parameters, such as the resulting particle residence time distribution at the outlet of the simulated volume, frequency shows a bigger influence. In comparison, narrower residence time distribution graphs also result in narrower distributions of other product properties which leads to an optimized product homogeneity. Besides the overall ranges of mean particle residence times, the corresponding shapes of particle residence time distributions are mostly bimodal and dependent on the investigated initial particle size as well as on the level of excitation under pulsating conditions. For the smallest investigated particles, the residence time distribution becomes narrower with frequencies from $80 \mathrm{~Hz}$ and above for pulsation amplitudes higher than the mean gas flow velocity compared to the stationary case. For pulsation amplitudes lower than or equal to the mean gas flow velocity, the frequency is still influential and delivers narrower distributions with increasing frequencies. However, particle residence time distributions are wider compared to the stationary flow for these simulation cases. For medium-sized particles, in comparison to the stationary flow case, the residence time distribution becomes narrower with frequencies from $80 \mathrm{~Hz}$ and above for pulsation amplitudes equal to the mean gas flow velocity. For the highest pulsation amplitude, this relation is valid for all frequencies. The behavior of medium-sized particles at pulsation amplitudes lower than the mean gas flow velocity is similar to the behavior of the smallest particles. The biggest particles show a constriction of the residence time distribution for all pulsating cases with sufficient pneumatic transport. A different and independent experimental study carried out by Alexander Schmidt [28] focusses on spray pyrolysis of the material system manganese nitrate to form manganese oxide. With a variation of the same frequencies $(40 ; 80$ and $160 \mathrm{~Hz})$, the influence on product homogeneity was studied for two particle sizes classes. Particle sizes were varied by two different atomization pressure settings. Homogeneity has been evaluated by the span of the particle size number distribution.

Comparing the values shown in Table 6, spans of particle size distributions become narrower with increased pulsation frequencies for both particle size classes, which is in accordance with the findings presented in this study. Comparing the stationary case with cases with pulsation, a similar result as in this presented study can be observed. For low particle sizes, the span of the particle-size number distribution is the lowest for the stationary case. For larger particle sizes, the span becomes smaller for frequencies from $80 \mathrm{~Hz}$ and above.

As a next step, representative experimental studies are carried out to validate the simulation results. On one hand, experiments consist of drying experiments, with a variation of the same parameters to identify the influences of pulsation parameters on particle-size distribution and moisture content. On the other hand, particle dynamics are analyzed with high speed camera caption and a transparent cylindrical volume of the same dimensions as used in the simulation studies to identify grouping and spout constriction behavior independent of the particle size and pulsation parameters applied. 
Table 6. Span of particle size number distribution for different particle sizes independent of pulsation frequency adapted from [28].

\begin{tabular}{ccc}
\hline Frequency in $\mathbf{H z}$ & \multicolumn{2}{c}{$\begin{array}{c}\text { Span of Number Particle Size Distribution } \\
{\left[\mathbf{s p a n}=\left(\mathbf{q}_{\mathbf{9 0 , 0} \mathbf{0}}-\mathbf{q}_{\mathbf{1 0 , 0} \mathbf{0}}\right) / \mathbf{q}_{\mathbf{5 0 , 0} \mathbf{0}}\right]}\end{array}$} \\
\hline & $\begin{array}{c}\text { High atomization pressure (low } \\
\text { particle sizes) }\end{array}$ & $\begin{array}{c}\text { Low atomization pressure (large } \\
\text { particle sizes) }\end{array}$ \\
\hline 0 "stationary" & 1.523 & 4.219 \\
40 & 3.286 & 4.700 \\
80 & 2.730 & 3.875 \\
160 & 1.923 & 3.813 \\
\hline
\end{tabular}

\section{Conclusions}

Based on the findings of this study, qualitative parameter sensitivities can be summarized (see Table 7). For example: An increase "+" of particle size results in an increase "+" of mean residence time at otherwise constant conditions. The increase of pulsation frequency has no or negligible " " influence on mean residence time. An increase of pulsation amplitude results in a restricted decrease "(-)" of the variance of distributed parameters. In this case, restricted means that the decrease is only valid while comparing simulation cases with pulsation. It is partly valid for stationary and pulsating conditions to be selected as simulation parameters, such as, e.g., biggest particles.

Table 7. Qualitative parameter sensitivities.

\begin{tabular}{cccc}
\hline Influenced Parameter & Particle Size & Pulsation Amplitude & Pulsation Frequency \\
\hline Mean residence time & + & - & \\
Mean particle temperature & $(-)^{1}$ & - & \\
Mean solids mass fraction & - & $(+)^{2}$ & \\
Mean heat and mass transfer & - & $(-)^{3}$ & $(-)^{3}$ \\
Variance of distributed parameters & + & - & + \\
Particle grouping & + & + & \\
Spout constriction & - & & \\
\hline only valid for biggest particles and maximum pulsation amplitude. ${ }^{2}$ only valid for medium and maximum \\
pulsation amplitude. ${ }^{3}$ only valid for comparison of cases with pulsation.
\end{tabular}

In conclusion, it can be outlined that by varying and applying appropriate pulsation parameters on pulsed multiphase flows for particle treatment, such as frequency and amplitude of pulsation in relation to the mean gas flow velocity, product particle properties can be tailored to the needs of the subsequent application by influencing distributed parameters or increasing the overall yield, although the mean values of the distributed parameters remain similar.

Author Contributions: Conceptualization, A.T.; methodology, A.T., M.D.; software, A.T., M.D.; validation, A.T., M.D.; formal analysis, A.T., M.D.; investigation, A.T.; resources, M.D., S.H.; data curation, A.T.; writing-original draft preparation, A.T.; writing—review and editing, A.T., M.D., M.J., S.H.; visualization, A.T.; supervision, M.D., M.J., S.H.; project administration, M.J. All authors have read and agreed to the published version of the manuscript.

Funding: This research received no external funding.

Conflicts of Interest: The authors declare no conflict of interest.

\section{Nomenclature}

$\begin{array}{ll}A & \text { area }\left(\mathrm{m}^{2}\right) \\ C_{A} & \text { 1st Antoine coefficient } \\ C_{B} & \text { 2nd Antoine coefficient } \\ C_{C} & \text { 3rd Antoine coefficient } \\ C_{D} & \text { drag coefficient (-) }\end{array}$




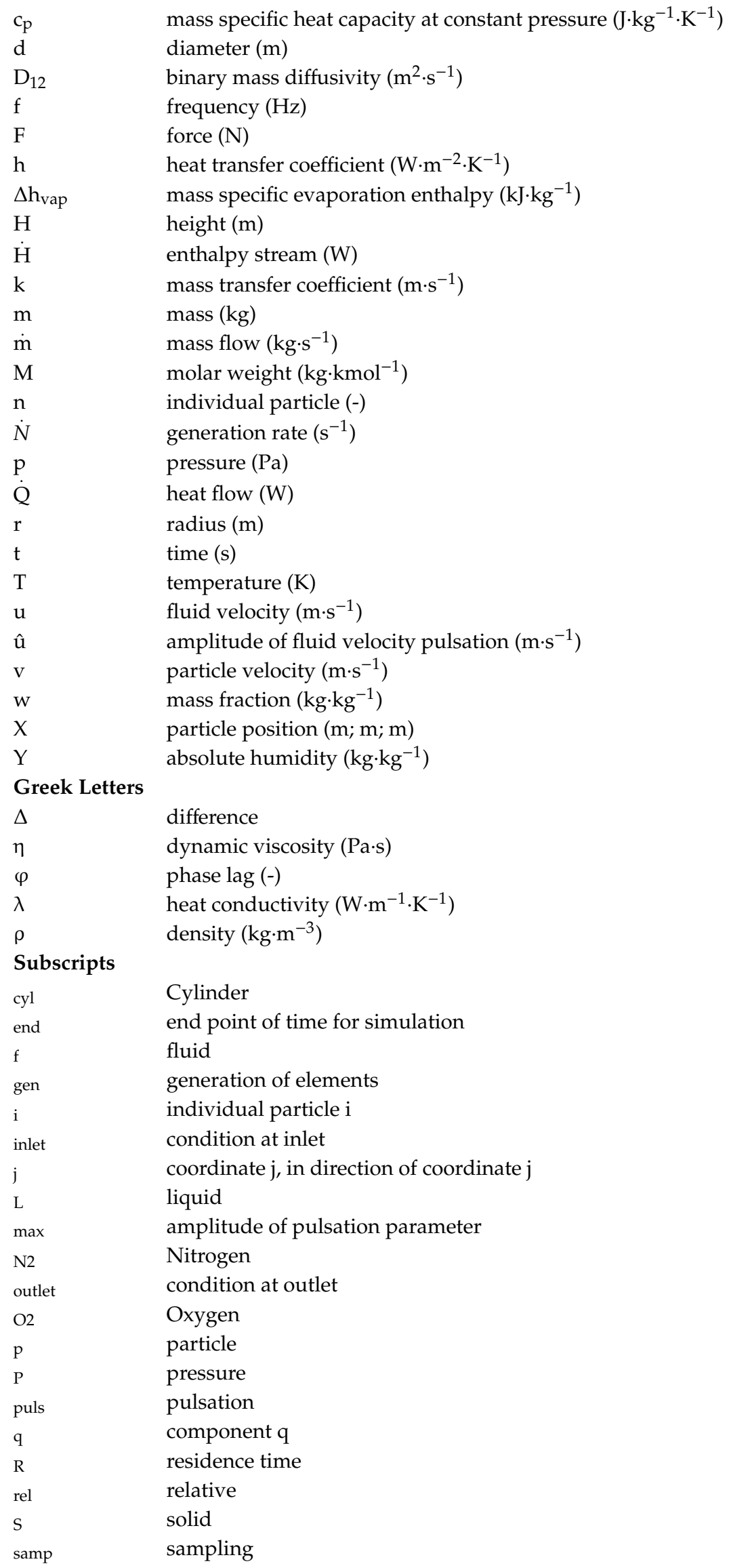




\begin{tabular}{|c|c|}
\hline sat & saturation \\
\hline save & saving data \\
\hline vap & vapor; evaporation \\
\hline $\mathrm{x}$ & coordinate $\mathrm{x}$; in direction of coordinate $\mathrm{x}$ \\
\hline $\mathrm{y}$ & coordinate $y$; in direction of coordinate $y$ \\
\hline $\mathrm{z}$ & coordinate $\mathrm{z}$; in direction of coordinate $\mathrm{z}$ \\
\hline 0 & initial condition \\
\hline \multicolumn{2}{|c|}{ Dimensionless Numbers } \\
\hline Co & Courant number (-) \\
\hline $\mathrm{Nu}$ & Nusselt number (-) \\
\hline $\operatorname{Pr}$ & Prandtl number (-) \\
\hline $\operatorname{Re}$ & Reynolds number (-) \\
\hline Sc & Schmidt number (-) \\
\hline Sh & Sherwood number (-) \\
\hline
\end{tabular}

\section{References}

1. Wold, A.; Gao, Y.-M.; Miller, D.; Kershaw, R.; Dwight, K. Chapter 19, Synthesis of catalytic materials by Spray Pyrolysis. In Advanced Catalysts and Nanostructured Materials, Modern Synthetic Materials, 1st ed.; Moser, W., Ed.; Academic Press: New York, NY, USA, 1996; pp. 505-514.

2. Jung, D.S.; Ko, Y.N.; Kang, Y.C.; Park, S.B. Recent progress in electrode materials produced by spray pyrolysis for next-generation lithium ion batteries. Adv. Powder Technol. 2014, 25, 18-31. [CrossRef]

3. Patil, P.-S. Versatility of chemical spray pyrolysis technique. Mater. Chem. Phys. 1999, 59, 185-198. [CrossRef]

4. Kudra, T. Pulse-combustion drying: Status and potentials. Drying Technol. 2008, 26, 1409-1420. [CrossRef]

5. Kudra, T.; Mujumdar, A.S. Advanced Drying Technologies, 2nd ed.; CRC Press: Boca Raton, FL, USA, 2009.

6. Widiyastuti, W.; Wang, W.; Purwanto, A.; Lenggoro, I.W.; Okuyama, K. A Pulse Combustion-Spray Pyrolysis Process for the Preparation of Nano- and Submicrometer-Sized Oxide Particles. J. Am. Ceram. Soc. 2007, 90, 3779-3785. [CrossRef]

7. Glatt Ingenieurtechnik GmbH: APPtec ${ }^{\circledR}$ Brochure; Glatt Ingenieurtechnik GmbH: Weimar, Germany, 2019.

8. Jacob, M.; Teiwes, A.; Jähnert, T. Glatt Ingenieurtechnik GmbH.; DE 102018205 152.6; Glatt Ingenieurtechnik GmbH: Weimar, Germany, 2018.

9. Meng, X.; Jong, W.; Kudra, T. A state-of-the-art review of pulse combustion: Principles, modeling, applications and R\&D issues. Renew. Sustain. Energy Rev. 2016, 55, 73-114.

10. Carvalho, J.A., Jr. Behaviour of solid particles in pulsating flows. J. Sound Vib. 1995, 185, 581-593. [CrossRef]

11. Sazhin, S.; Shakked, T.; Sobolev, V.; Katoshevski, D. Particle grouping in oscillating flows. Eur. J. Mech. B/Fluids 2008, 27, 131-149. [CrossRef]

12. Liu, X.D.; Cao, C.W.; Lang, Z.H. Heat transfer between materials and unsteady airflow from Helmholtz type combustor. Dry. Technol. 2001, 19, 1939-1948. [CrossRef]

13. Kudra, T.; Benali, M.; Zbicinski, I. Pulse Combustion Drying: Aerodynamics, Heat Transfer, and Drying Kinetics. Dry. Technol. 2003, 21, 629-655. [CrossRef]

14. Mahapatraa, P.S.; Mukhopadhyay, A.; Panchagnula, M.V. Dispersion of Polydisperse Droplets in a Pulsating Flow Field. Procedia IUTAM 2015, 15, 242-248. [CrossRef]

15. Xiao, Z.; Xie, X.; Yuan, Y.; Liu, X. Influence of Atomizing Parameters on Droplet Properties in a Pulse Combustion Spray Dryer. Dry. Technol. 2008, 26, 427-432. [CrossRef]

16. Dong, L.; Zhao, Y.; Xie, W.; Duan, C.; Li, H.; Hua, C. Insights in active pulsing air separation technology for coarse coal slime by DEM-CFD approach. J. Cent. South. Univ. 2013, 20, 3660-3666. [CrossRef]

17. Dosta, M.; Antonyuk, S.; Heinrich, S. Multiscale simulation of fluidized bed granulation process. Chem. Eng. Technol. 2012, 35, 1373-1380. [CrossRef]

18. Heinrich, S.; Dosta, M.; Antonyuk, S. Multiscale analysis of a coating process in a Wurster fluidized bed apparatus. In Mesoscale Modeling in Chemical Engineering Part I.; Guy, B.M., Jinghai, L., Eds.; Advances in Chemical Engineering, Academic Press: London, UK, 2015; pp. 83-135.

19. Dosta, M. Modular based simulation of single process units. Chem. Eng. Technol. 2019, 42, 699-707. [CrossRef]

20. Weller, H.G.; Tabor, G.; Jasak, H.; Fureby, C. A tensorial approach to computational continuum mechanics using object-oriented techniques. Comput. Phys. 1998, 12, 620-631. [CrossRef] 
21. Courant, R.; Friedrichs, K.; Lewy, H. Über die partiellen Differenzengleichungen der mathematischen Physik. Math. Ann. 1928, 100, 32-74. [CrossRef]

22. VDI e.V. (Hrsg.). VDI-Wärmeatlas@; Springer-Verlag: Berlin/Heidelberg, Germany, 2013.

23. Molerus, O. Principles of Flow in Disperse Systems; Chapman \& Hall: Berlin, Germany, 1993.

24. Ranz, W.E.; Marshall, W.R. Evaporation from drops. Chem. Eng. Prog. 1952, 48, 141-146.

25. Aissa, A.; Abdelouahab, M.; Noureddine, A.; Elgananoui, M.; Pateyron, B. Ranz \& Marshall correlation limits for a sphere and its surrounding gases at high temperature. Thermal Sci. 2015, 19, 1521-1528.

26. Fuller, E.N.; Ensley, K.; Giddings, J.C. Diffusion of halogenated hydrocarbons in helium. The effect of structure on collision cross sections. J. Phys. Chem. 1969, 73, 3679-3685. [CrossRef]

27. Dosta, M.; Antonyuk, S.; Heinrich, S. Multiscale simulation of agglomerate breakage in fluidized beds. Ind. Eng. Chem. Res. 2013, 52, 11275-11281. [CrossRef]

28. Schmidt, A. Experimentelle Prozessanalyse der Sprühkalzination von Mangandioxid im pulsierenden Heißgasstrom. Master's Thesis, University of Applied Science-Ernst-Abbe-Hochschule Jena, Jena, Germany, 2020 .

(C) 2020 by the authors. Licensee MDPI, Basel, Switzerland. This article is an open access article distributed under the terms and conditions of the Creative Commons Attribution (CC BY) license (http://creativecommons.org/licenses/by/4.0/). 